\title{
The Dependency of Diffusion Coefficients and Geometric Factor on the Size of the Diffusing Molecule: Observations for Different Clay-Based Materials
}

\author{
Elke Jacops, ${ }^{1,2,3}$ Marc Aertsens, ${ }^{1}$ Norbert Maes, ${ }^{1}$ Christophe Bruggeman, ${ }^{1}$ Rudy Swennen, \\ Bernd Krooss, ${ }^{3}$ Alexandra Amann-Hildenbrand, ${ }^{3}$ and Ralf Littke ${ }^{3}$ \\ ${ }^{1}$ Belgian Nuclear Research Centre (SCK・CEN), Mol, Belgium \\ ${ }^{2}$ KU Leuven, Heverlee, Belgium \\ ${ }^{3}$ RWTH Aachen University, Aachen, Germany \\ Correspondence should be addressed to Elke Jacops; ejacops@sckcen.be
}

Received 7 June 2017; Accepted 29 October 2017; Published 27 December 2017

Academic Editor: Ian Clark

Copyright ( 2017 Elke Jacops et al. This is an open access article distributed under the Creative Commons Attribution License, which permits unrestricted use, distribution, and reproduction in any medium, provided the original work is properly cited.

\begin{abstract}
In order to investigate in more detail the relation between the size of diffusing molecules and their diffusion coefficients (and geometric factors), diffusion experiments with gases of different size and tritiated water (HTO) have been performed on different clayey samples (Boom Clay, Eigenbilzen Sands, Opalinus Clay, Callovo-Oxfordian Clay, and bentonite with different dry densities). We observed that, for unreactive gases in clayey materials, the effective diffusion coefficient varies with the size of the diffusing molecule and this variation can be described by an exponential or a power law function. The variation of the geometric factor can also be described by an exponential function. The observed experimental relations can be used to estimate diffusion coefficients; by measuring experimentally in clay the effective diffusion coefficient of two unreactive dissolved gases with a different size, the diffusion coefficients of other dissolved gases (with a size in between the two measured gases) can be estimated by using the fitted exponential relationship.
\end{abstract}

\section{Introduction}

Clay-based materials are considered by many countries in their concepts for the safe disposal of high- and intermediatelevel radioactive waste, either as the material of choice in the engineered barrier system or because of the choice of argillaceous formations to host the repository. Examples of European countries where argillaceous formations are being explored as potential host formations are Belgium, Switzerland, and France [1-3]. The use of clay-based materials as engineered barriers is studied in, for example, Switzerland [4], France [5], and Sweden [6]. The clays under consideration all have a high sorption capacity for many radionuclides [7-9], a low hydraulic conductivity [10, 11], and interesting self-sealing properties $[12,13]$.

In Belgium, no formal decision has been taken yet on a host formation, but for R\&D purposes, the Belgian Radioactive Waste Management Organization (ONDRAF/NIRAS) considers Boom Clay (BC) as a potential host formation for a geological disposal facility. In France, the National Agency for Radioactive Waste Management (Andra) selected the Callovo-Oxfordian Clay Formation in the east of France as a potential host formation [14] and in Switzerland the National Cooperative for the Disposal of Radioactive Waste (NAGRA) proposed the Jurassic Opalinus Clay (OPA) as a host. As engineered barrier, mainly bentonite is studied. A frequently used type of bentonite is MX80, which is studied as backfill material by Andra [5, 15], NAGRA [4], and the Swedish Nuclear Fuel and Waste Management Co. (SKB) [16, 17].

In the context of nuclear waste disposal, the transport of dissolved gases in compacted clays is an area, which receives a high amount of interest. First, the production of gas within a geological repository is unavoidable. Mainly anaerobic corrosion of metals will lead to the production of hydrogen. If the rate of gas generation is larger than the diffusive flux into the clay, a free gas phase will form, which might have a 
negative effect on the performance of the barriers. In order to compute a comprehensive and reliable balance between gas generation versus gas dissipation, correct estimates for gas diffusion coefficients of dissolved gases are essential. Moreover, the produced hydrogen may be converted to other gases like $\mathrm{CH}_{4}$ due to, for example, microbial activity. Thus, also the diffusion coefficient of methane needs to be established.

Secondly, naturally occurring noble gases such as He and Ar can act as natural tracers whose profiles can be used to constrain transport properties on the scale of the formation [18-20]. As diffusion is considered to be the dominant transport mechanism, it should be possible to represent these natural tracer profiles by diffusion models, but the availability of reliable diffusion coefficients for $\mathrm{He}$ and Ar is limited.

Measuring reliable diffusion coefficients of gases is not evident [21] and only a limited amount of data is available in the literature [22]. Recently, diffusion coefficients of dissolved gases ( $\mathrm{He}$ and $\mathrm{Ar}$ ) have been measured in Boom Clay, Callovo-Oxfordian Clay, and Opalinus Clay and results have been reported by Jacops et al. [22] and Jacops et al. [23].

In case of hydrogen, Jacops et al. [24] have shown that diffusion experiments with hydrogen often suffer from microbial activity: here methanogenic microbes convert $\mathrm{H}_{2}$ into $\mathrm{CH}_{4}$, making the accurate determination of diffusion coefficients impossible [24]. Similar observations have been reported by Vinsot et al. [25].

When performing scoping calculations on the diffusive mobility and possible build-up of dissolved gases in a geological repository or in a geological formation, reliable gas diffusion coefficients obtained from laboratory experiments are often not available. Hence, these diffusion coefficients are often estimated from measured values of other species like HTO. In case of hydrogen, the diffusion coefficient for helium is often used as a surrogate. In this approach, it is implicitly assumed that the geometric factor of the formation (a factor which describes the effect of the porous network on diffusion and for which the value obtained for HTO is used) is equal for all other gases and species considered (e.g., [26]).

Different approaches for estimating the geometric factor exist: for example, (i) from diffusion experiments (mostly with HTO $[26,27]$ ), (ii) by models (e.g., [28-31]), or (iii) from diffusion simulations on reconstructed clay structures $[32,33]$. Archie's law [28] is a well-known empirical relation relating diffusivity to porosity (but neglecting constrictivity). Variations on Archie's law are proposed, for example, by Weissberg [34] and Boudreau [29]. Saripalli et al. [30] described a method to calculate tortuosity and constrictivity from the specific surface determined from, for example, $\mathrm{N}_{2}$ adsorption measurements. Chou et al. [31] discussed models to calculate tortuosity for variously saturated soil samples, based on their water content. Both Robinet et al. [32] and Keller et al. [33] calculated geometric factors from diffusion simulations on reconstructed mesostructures of, respectively, the Callovo-Oxfordian and the Opalinus Clay. Their developed approach allows the determination of the geometric factor as a function of mineralogy. All these methods calculate the geometric factor as an intrinsic parameter of a specific material, without taking into account the possible effect of the size of the diffusing molecule.

In clay, a relation between the size of the diffusing molecule (expressed by the kinetic diameter) and its diffusion coefficient has been observed $[22,23]$. The effect of the size of diffusing molecules on its diffusion coefficient in CallovoOxfordian Clay has also been discussed by Dagnelie et al. [35]. For anions, a relation was shown between the anion size (expressed as $M^{1 / 3}$ with $M$ the molecular mass) and the ratio of aqueous diffusion coefficients $D_{0} / D_{0}{ }^{\mathrm{HTO}}$. For cations, a similar relation exists but size is expressed as $1 /$ hydrated radius.

For mortars with a different sand content, the measured geometric factors for $\mathrm{Li}^{+}, \mathrm{Cl}^{-}$, and HTO are relatively similar, leading to the conclusion that the formation factor can be used to determine the order of magnitude of the effective diffusion coefficient of other diffusion species [36]. Analyses of these data indicate a variability of the geometric factor with the size of the diffusing molecule, but this is less pronounced due to the similar size of $\mathrm{Li}^{+}, \mathrm{Cl}^{-}$, and HTO. The dependence of the geometric factor on the size of the diffusion molecule is demonstrated in diffusion experiments with $\mathrm{He}, \mathrm{O}_{2}$, and $\mathrm{Xe}$ in mortars (unpublished data).

The main objective of this paper is to investigate in more detail the relation between the size of the diffusing gas molecules and their diffusion coefficients and hence geometric factors in different clayey materials. We also investigate whether this relation can be used to estimate diffusion coefficients of gases, based on their size.

This objective is achieved by performing diffusion experiments with gases of different size, on different clayey samples (Boom Clay, Eigenbilzen Sands, Opalinus Clay, CallovoOxfordian Clay, and bentonite (Volclay KWK with different dry densities)).

\section{Materials and Methods}

2.1. Clay Samples. The Boom Clay is a marine sediment that was deposited in the early Oligocene (Rupelian), 29 to 32 million years ago in the North Sea Basin, at water depths between 50 and $100 \mathrm{~m}$ [37]. Shortly after deposition, the accumulated sediment became reducing which is reflected in the common occurrence of framboidal pyrite. The Boom Clay comprises clay minerals (up to $60 \%$, dominated by illite, mixed layered illite-smectite, kaolinite, and traces of chlorite), as well as quartz, $\mathrm{K}$-feldspar, $\mathrm{Na}$-plagioclase, pyrite, and carbonates [38]. It consists of different lithological subunits; more specifically a rhythmic alteration of silty and more clay-rich layers has been observed, as well as the presence of organic- and carbonate-rich layers. Based on these lithological variations, the Boom Clay has been subdivided in four members: the Boeretang Member, the Putte Member, the Terhagen Member, and the BelseleWaas Member [37]. The sandy unit lying above the Boom Clay is named the Eigenbilzen Sands. The latter consists of dark green, glauconite-rich, clayey, fine-grained to mediumgrained sands, with bioturbations [39]. The amount of fine sand increases significantly but the alternation of silty and clayey intervals as observed in the Boom Clay remains [37]. 
TABLE 1: Overview of used samples with the SCK ID, core number, type, and orientation with respect to the bedding.

\begin{tabular}{|c|c|c|c|c|}
\hline Material & SCK ID & Core \# & Type & Orientation \\
\hline Boom Clay & K2 & ON-Mol-1 84b & Clay & $\perp$ \\
\hline Boom Clay & K4 & ON-Mol-1 127b & Clay & $/ /$ \\
\hline Eigenbilzen Sands & K14 & ON-Mol-1 36a & Clayey sand & $/ /$ \\
\hline Eigenbilzen Sands & K15 & ON-Mol-1 37b & Clayey sand & $/ /$ \\
\hline Eigenbilzen Sands & K16 & ON-Mol-1 35b & Clayey sand & $\perp$ \\
\hline Eigenbilzen Sands & K17 & ON-Mol-1 39b & Clayey sand & $\perp$ \\
\hline Volclay KWK & Bentonite 1.4 & & Dry density $1.4 \mathrm{~g} / \mathrm{cm}^{3}$ & \\
\hline Volclay KWK & Bentonite 1.6 & & Dry density $1.6 \mathrm{~g} / \mathrm{cm}^{3}$ & \\
\hline Callovo-Oxfordian Clay & $\mathrm{COX}$ & EST 49109 & Claystone & $\perp$ \\
\hline Opalinus Clay & OPA & Schlattingen $860.32 \mathrm{~m}$ depth & Claystone & $\perp$ \\
\hline
\end{tabular}

Samples from this formation are in this work described as "clayey sand."

One of the topics under investigation is the effect of variations in the clay and silt/sand content on the diffusion parameters [23]. Therefore, samples have been selected based on their location in the lithostratigraphic column. The clayey samples originate from the Putte or Terhagen Member, whereas the clayey sand samples originate from the Eigenbilzen Sands. Whether the samples are a representative selection or not is investigated by mineralogical analyses, by grain size analyses, and by measuring the hydraulic conductivity. More information on the origin of the used samples and their orientation with respect to bedding plane can be found in Table 1 .

All samples from the Boom Clay and Eigenbilzen Sands used in this study are taken from the ON-Moll borehole which was drilled in 1997, in the town of Mol, in the northeast of Belgium (Lambert coordinates $X(\mathrm{~m}) 200191.278$ and $Y(\mathrm{~m})$ 211651.761). The samples have been stored under anoxic conditions (vacuum packed in aluminium-coated PE-foil) at $4^{\circ} \mathrm{C}$. Prior to their use, they were visually inspected for signs of oxidation which is the main quality threat and the main indicator for perturbations and deteriorations, which might have occurred during storage.

The Callovo-Oxfordian Clay (COX) is an indurated, Middle Jurassic mudstone from marine origin, which was deposited 150-160 million years ago. It has been intensively studied by Andra on a $250 \mathrm{~km}^{2}$ area. In this area, Andra has performed several drilling campaigns and constructed an Underground Research Laboratory (URL) in Bure, at a depth of $490 \mathrm{~m}$ in the COX layer. The thickness of the COX formation is about $135 \mathrm{~m}$ at the URL. The COX consists mainly of clay minerals (illite, interstratified smectite/illite, and others), calcite, dolomite/ankerite, quartz, feldspars, and minor amounts of accessory phases, such as pyrite [40]. The used sample (EST 49109; depth, $478.52 \mathrm{~m}$ ) was taken from the OHZ6560 borehole, which has been drilled from a technical gallery at the URL. The sample axis is oriented perpendicular to the bedding plane.

The Opalinus Clay is a fine-grained sedimentary rock, which was deposited 172 million years ago. The latter consists mainly of clay minerals (illite, illite/smectite, kaolinite, and others), calcite, dolomite/ankerite, quartz, feldspars, pyrite, and organic matter. Research on the Opalinus Clay is mainly performed in the Mont Terri Underground Research Lab, located in the canton Jura. The studied sample was, however, taken from the Schlattingen borehole (Northeast of Switzerland, canton Thurgau), at a depth of $860.32 \mathrm{~m}$ below surface. As the burial history for the Mont Terri site and Schlattingen is different, with deeper burial in Schlattingen [41], the physical properties of the Opalinus Clay are different at both locations. The sample axis is oriented perpendicular to the bedding plane.

The Volclay KWK (a MX 80 type bentonite) is a finegrained sodium bentonite with montmorillonite as the main component [42]. This type of bentonite was selected because it was characterized within the NF-PRO project [43] and a batch was readily available at SCK•CEN. Besides, a similar type of bentonite was used as a sealing material within the PRACLAY heater experiment which is performed in the HADES URL [44]. Two different bentonite samples were used, each compacted at different dry densities (1.4 and $\left.1.6 \mathrm{~g} / \mathrm{cm}^{3}\right)$.

2.2. Sample Preparation. For the experimental setup of the design of the diffusion cell, see Jacops et al. [21]. The Boom Clay sample (diameter $80 \mathrm{~mm}$, length $30 \mathrm{~mm}$ ) was loaded into the diffusion cell with a hydraulic press. Confinement (constant volume) was achieved by sealing the diffusion cell (welding). Due to the high plasticity and swelling capacity [12] perfect sealing between clay and cell was achieved. Porous stainless steel filter plates (diameter $80 \mathrm{~mm}$; thickness $2 \mathrm{~mm}$; porosity 40\%; GKN Sinter Metals) were used at both sides. This provided a good contact between the gas-saturated water and the clay.

As Callovo-Oxfordian Clay and Opalinus Clay contain lower proportions of swelling clay minerals, their swelling capacity/plasticity is therefore much lower compared to the Boom Clay. Hence, the samples had to be embedded in a resin (Sikadur 52 Injection Normal) in order to seal the interface clay sample-cell. The embedded samples $(80 \mathrm{~mm}$ diameter and $25 \mathrm{~mm}$ height for Opalinus Clay and $70 \mathrm{~mm}$ diameter and $30 \mathrm{~mm}$ height for the Callovo-Oxfordian Clay) were placed between an upper and lower flange, and subsequently the flanges were welded to the diffusion cell (confinement with constant volume). As the flanges were provided with a 
circulation loop, good contact between the water containing the dissolved gas and the clay sample was ensured. More information on the preparation of these samples can be found in Jacops et al. [23] and Jacops et al. [22].

The Volclay KWK was compacted to two different dry densities, that is, 1.4 and $1.6 \mathrm{~g} / \mathrm{cm}^{3}$. Prior to the compaction, the water content of the batch was measured by drying at $105^{\circ} \mathrm{C}$ for at least 24 hours. The correct amount of bentonite was compacted into a cylinder of 20 by $20 \mathrm{~mm}$. Next, the compacted samples were saturated with a synthetic pore water of $0.05 \mathrm{M} \mathrm{NaClO}_{4}$.

2.3. Sample Characterization. For mineralogical analyses samples were grinded first with mortar and pestle and afterwards (after adding ethanol) in a McCrone Micronizing Mill. After drying, the residue was crushed again with mortar and pestle and finally it was packed in the sample holder [45]. Mineralogy was determined by X-ray diffraction (XRD) analyses as described by [46]. The mineralogy of the Opalinus Clay sample was determined by the University of Bern [47].

The specific surface area was measured by nitrogen adsorption at $77 \mathrm{~K}$ in a TriStar 3020 (Micromeritics), using the Brunauer-Emmett-Teller theory. Prior to the measurement, ca. $3 \mathrm{~g}$ sample was degassed at $110^{\circ} \mathrm{C}$. Next, the pressure of $\mathrm{N}_{2}$ was gradually increased and the amount of adsorbed gas was measured as a function of the relative pressure, which plots the adsorption isotherm.

Once the diffusion experiments ended, the porosity was determined by drying the samples at $105^{\circ} \mathrm{C}$ until the mass was stable. Based on the mass loss during drying and the density, the porosity could be calculated [48].

2.4. Hydraulic Conductivity. Hydraulic conductivity was measured prior to the diffusion experiment. The used technique is based on Darcy's law and applies a constant pressure difference [49]. The sample was considered to be saturated when water outflow and inflow were equal in at least five successive measurements.

2.5. Diffusion of Dissolved Gases. The methodology of through-diffusion experiments has been described in detail in Jacops et al. [21]. Only the main aspects are repeated here. The basis is the double through-diffusion technique [50]. Both sides of the test core were connected to a water vessel filled with circa $500 \mathrm{~mL}$ oxygen-free synthetic pore water and pressurised with a gas (circa $500 \mathrm{~mL}$ gas at $1 \mathrm{MPa}$ ). The composition of the pore water used for Boom Clay, and Eigenbilzen Sands, Callovo-Oxfordian Clay, and Opalinus Clay can be found in Jacops et al. [22] and for the bentonite samples, degassed demineralised water with $0.05 \mathrm{M}$ $\mathrm{NaClO}_{4}$ was used. Both vessels were filled with a different gas, but the total pressure was the same. In this way, no advective flux could occur and the clay sample remained fully water saturated. According to Henry's law, equilibrium was obtained between the free gas in the gas phase and the dissolved gas in the water. The water at both sides was then circulated over the filters, which were in contact with the clay core, allowing the dissolved gases to diffuse through the clay core, towards the reservoir on the opposing side. The change in gas composition in both reservoirs was measured as a function of time by gas chromatography.

Sampling of the gas phase was performed on a regular basis (generally once per week) until 10 data points were obtained in the regime of approximately constant outlet flux of the diffusion process. The gas composition was analysed with a CP4900 micro GC (equipped with a Molsieve 5A and a Pora Plot U column and TCD detectors, Agilent, USA) or a CG4 Compact GC (equipped with a RT-Qbond column, a Molsieve 5A column and TCD detectors, Interscience, The Netherlands). Both GCs were operated with the EZChrom CDS software.

The experiment was performed in a temperaturecontrolled room $\left(21 \pm 2^{\circ} \mathrm{C}\right)$.

The diffusion experiments with several gases on the same sample were performed consecutively: the content of the inlet and outlet vessel was replaced each time while the sample remained in the same position.

2.6. Diffusion of HTO. In order to allow comparison of our results with available results in literature, diffusion experiments with HTO were performed with a setup similar to the one used to measure through-diffusion of dissolved gases. A more detailed description can be found in Jacops et al. [23]. The water vessels were filled with $250 \mathrm{~mL}$ synthetic pore water and $250 \mathrm{~mL}$ Ar at $1 \mathrm{MPa}$. A HTO spiking solution of approximately $50 \mathrm{kBq}$ was added in the high concentration compartment. Both the decrease in activity in the high concentration compartment and the increase in the low concentration compartment were measured by taking at each side two samples of $1 \mathrm{~mL}$. The water in both compartments was not replaced during the experiment. Sampling occurred regularly (once or twice per week) until 10 data points were obtained in the regime of approximately constant outlet flux. Samples were analysed for their radioactivity with a Packard TRI-CARB 2100TR liquid scintillation counter.

\section{Theory and Modelling}

3.1. Diffusion Theory. The theoretical aspects of diffusion are discussed in detail in Jacops et al. [23] and only some aspects are discussed below.

In general, two transport parameters can be obtained from diffusion experiments: the apparent diffusion coefficient $D_{\text {app }}\left(\mathrm{m}^{2} / \mathrm{s}\right)$ and the capacity factor $\eta R$, being the product of the accessible porosity $\eta$ (dimensionless) and the retardation factor $R$ (dimensionless). The capacity factor is the ratio of the tracer concentration $C_{b}$ in the bulk sample and the corresponding concentration $C$ in the pore fluid (solution): $\eta R=C_{b} / C$.

From these two basic parameters, one can calculate the effective diffusion coefficient $D_{\text {eff }}\left(\mathrm{m}^{2} / \mathrm{s}\right)$

$$
D_{\text {eff }}=\eta R D_{\text {app }}
$$

and, assuming the accessible porosity equals the total porosity $\eta_{\text {tot }}$, the pore diffusion coefficient $D_{p}\left(\mathrm{~m}^{2} / \mathrm{s}\right)$

$$
D_{p}=R D_{\text {app }} \text {. }
$$


For unretarded species without ion exclusion (e.g., HTO, noble gases), the retardation factor is generally taken equal to one $(R=1)$, leading to $D_{\text {app }}=D_{p}$ and a capacity factor equal to the total porosity $\eta_{\text {tot }}$.

The geometric factor $G$ relates the diffusion coefficient in a porous medium to the corresponding diffusion coefficient $D_{0}\left(\mathrm{~m}^{2} / \mathrm{s}\right)$ in water and is defined by

$$
G=\frac{D_{0}}{D_{p}}=\frac{D_{0}}{R D_{\text {app }}}=\frac{\eta D_{0}}{D_{\text {eff }}} .
$$

Although the geometric factor is a black box factor, it is often split into two dimensionless factors: tortuosity $\tau$ and constrictivity $\delta$,

$$
G=\frac{\tau}{\delta}
$$

In this expression, used in the present paper and Grathwohl [51], tortuosity is defined as the square of the ratio of the effective path length (along the path) of a diffusing component to the shortest distance (end-to-end distance) of that path. Constrictivity takes into account the reduction of the effective diffusion coefficient due to a drag by the pore wall and depends on the ratio of the solute diameter to the pore diameter.

Grathwohl [51] lists some empirical expressions for constrictivity, for example,

$$
\delta=\exp \left(-4.6 \frac{\sigma}{R_{\text {pore }}}\right),
$$

with $\sigma$ the size (diameter) $(\mathrm{m})$ of the diffusing molecule and $R_{\text {pore }}$ the pore width (diameter) (m). Substituting (5) into (4) leads to

$$
G=\tau \exp \left(4.6 \frac{\sigma}{R_{\text {pore }}}\right) .
$$

Evidently, reducing the pore size distribution of clay to a single pore size $R_{\text {pore }}$ is an enormous simplification as clays have in reality a wide pore size distribution. In expression (6), like in reality, the influence of the size of the diffusing molecule $\sigma$ depends on the ratio of molecular size to pore width. Although empirical (and certainly not valid over the entire $\sigma / R_{\text {pore }}$ range), expression (6) also takes into account that sufficiently large molecules $(\sigma \rightarrow \infty)$ can no longer diffuse through the clay anymore $(G \rightarrow \infty$ corresponding to a zero effective/apparent/pore diffusion coefficient). This has been observed, for example, for the transport of colloids (natural organic matter) in Boom Clay [52], where small sized diffusing molecules can move through the clay while larger ones cannot. This is related to a percolation transition [53]. If the size of the diffusing molecule rises, fewer pores are available for the transport (diffusion) of that molecule. In a first stage, this will lead to longer travel paths ("tortuosity") since only pores with a pore size larger than the size of the diffusing molecule are available. When still increasing the molecular size, there is no longer a connected path (of pores available for transport) between the larger pores and the diffusion coefficient becomes zero. In the remainder of this paper, expression (6) is used as a simple empirical expression, trying to capture the evolution of the $G$-factor as a function of size of the diffusing molecule (but clearly wrong when $\sigma / R_{\text {pore }} \gg 1$ ), which does not imply the approval of expression (4) and the corresponding definition of tortuosity and constrictivity.

3.2. Single Pore Size Hydraulic Conductivity Model. Due to the single pore size approximation in the $G$-factor, also a single pore size model is presented for advective flow. The flow $Q_{\text {core }}$ $\left(\mathrm{m}^{3} / \mathrm{s}\right)$ out of a cylindrical clay core with radius $R_{\text {core }}(\mathrm{m})$ and length $L_{\text {core }}(\mathrm{m})$ is provided by Darcy's law,

$$
Q_{\text {core }}=\pi R_{\text {core }}^{2} \frac{\Delta p}{L_{\text {core }}} K
$$

with $\Delta p$ being the pressure difference (in meter water column) over the core.

Poiseuille's law gives the flow $Q_{\text {pore }}\left(\mathrm{m}^{3} / \mathrm{s}\right)$ through a cylindrical pore with radius $R_{\text {pore }}(\mathrm{m})$

$$
Q_{\text {pore }}=\frac{1}{\mu} \frac{\pi R_{\text {pore }}^{4}}{8} \frac{\Delta p}{L_{\text {core }}}
$$

with $\mu$ being the viscosity $(\mathrm{kg} /(\mathrm{ms})$ ) (a value $\mu=$ $0.7978 \mathrm{mPa} \mathrm{s}=8.135 \times 10^{-8} \mathrm{~m} \mathrm{~s}$ was used (Edge Engineers))

If $C_{\text {pore }}$ is the number of pores per unit surface $\left(\mathrm{m}^{-2}\right)$, the flow $Q_{\text {core }}$ also equals

$$
Q_{\text {core }}=\pi R_{\text {core }}^{2} C_{\text {pore }} Q_{\text {pore }}
$$

and the core porosity $\eta_{\text {tot }}$ is given by

$$
\eta_{\mathrm{tot}}=\pi R_{\text {pore }}^{2} C_{\text {pore }}
$$

Combining expressions (7)-(10) leads to the next expression for the hydraulic conductivity

$$
K=\frac{1}{8 \mu} R_{\text {pore }}^{2} \eta_{\text {tot }}=\frac{\pi}{8 \mu} R_{\text {pore }}^{4} C_{\text {pore }}
$$

showing that, for two clays with the same porosity, the hydraulic conductivity is the highest for the clay with the largest pore size. It is also clear that, in case of a pore size distribution, a major contribution to the hydraulic conductivity comes from the largest pores.

3.3. Size of the Diffusing Molecules. The size of a diffusing molecule can be characterized in several ways. As it would be not appropriate to use values which have been determined from diffusion measurements (hence leading to circular reasoning), some extra clarification on the selection of the kinetic diameters is given in this paragraph. The most widely used measure for the size of a (small) gas molecule is the kinetic diameter $(\sigma)$ [54]. In this approach, the interaction potential between two (gas) molecules is assumed a LennardJones $V_{\mathrm{LJ}}(r)$ potential (with $r$ distance between the centre of two molecules) [55]. 
The potential $V_{\mathrm{LJ}}(r)$ is zero at $r=\sigma$ and the distance $\sigma$ (called the kinetic diameter) is considered representative for the size of the gas molecule. For the kinetic diameters used in this work, the parameters of the Lennard-Jones potential are derived from viscosity measurements at different temperatures.

However, the selected kinetic diameters are representative for dilute gas mixtures and are thus only an approximation for gases dissolved in water. More information on this topic can be found in [23].

3.4. Size Dependency of the Diffusion Coefficient of Gases in Water and Clay. Empirically, the gas diffusion coefficients $D_{0}$ in water were fitted as a function of the kinetic diameter $\sigma$ (expressed in $10^{-10} \mathrm{~m}$ ) by an exponential equation

$$
D_{0}=D_{0, \exp } \exp \left(-n_{0, \exp } \sigma\right)
$$

leading to $D_{0, \exp }=(5.5 \pm 2.3) \times 10^{-8} \mathrm{~m}^{2} / \mathrm{s}$ and $n_{0, \exp }=(8.8 \pm$ 1.2) $\times 10^{9} \mathrm{~m}^{-1}[23]$. Another possibility is a power law fit

$$
D_{0}=D_{0, \text { pow }} \sigma^{-n_{0, \text { pow }}}
$$

leading to $D_{0, \text { pow }}=(1.1 \pm 0.46) \times 10^{-7} \mathrm{~m}^{2} / \mathrm{s}$ and $n_{0, \text { pow }}=$ $3.0 \pm 0.4$ [23]. Because expressions (12) and (13) do not take into account details like molecular geometry or polarity of a molecule, they only describe a global evolution without predicting correctly every single point (like, e.g., Archie's law).

Similar to the diffusion coefficient $D_{0}$ in free water, for gases (and HTO) trend lines for the dependence of the effective diffusion coefficient $D_{\text {eff }}$ on the kinetic diameter $\sigma$ are fitted by assuming similar expressions as (12) and (13) [23]:

$$
\begin{aligned}
& D_{\text {eff }}=D_{\text {eff,exp }} \exp \left(-n_{\text {exp }} \sigma\right), \\
& D_{\text {eff }}=D_{\text {eff,pow }} \sigma^{-n_{\text {pow }}} .
\end{aligned}
$$

Substituting (12) and (14) into (1) provides for unretarded tracers without ion exclusion (the retardation factor $R=1$ ) an expression for the geometric factor:

$$
G=\eta \frac{D_{0, \exp }}{D_{\text {eff,exp }}} \exp \left(\left(n_{\exp }-n_{0, \exp }\right) \sigma\right) .
$$

This expression reduces to the Gratwohl expression (6) by putting

$$
\begin{aligned}
\tau & =\eta \frac{D_{0, \exp }}{D_{\text {eff,exp }}} \\
R_{\text {pore }} & =\frac{4.6}{n_{\exp }-n_{0, \exp }},
\end{aligned}
$$

where a positive pore size $R_{\text {pore }}$ requires that $n_{\text {exp }}>n_{0 \text {,exp }}$.

A similar combination as (16) can be made with expressions (13) and (15) leading to (and assuming $n_{\text {pow }}>=n_{0, \text { pow }}$ )

$$
G=\eta \frac{D_{0, \text { pow }}}{D_{\text {eff,pow }}} \sigma^{\left(n_{\text {pow }}-n_{0, \text { pow }}\right)} .
$$

An expression similar to (17) can be defined for the power law (19), but no characteristic distance similar to $R_{\text {pore }}$ exists. Also note that with the power law, $G(\sigma=0)=0$ (assuming $\left.n_{\text {pow }}>=n_{0, \text { pow }}\right)$ instead of $G(\sigma=0)=\tau$ for the exponential relation (16).

3.5. Modelling. A detailed description on the modelling approach can be found in Jacops et al. [23].

The diffusion experiments are modelled by fitting the solutions of the diffusion equation with the appropriate boundary and initial conditions. For both the gas diffusion and the HTO diffusion experiments, the diffusion equation is solved by COMSOL coupled with MATLAB for optimization.

A through-diffusion experiment allows fitting both the apparent diffusion coefficient $D_{\text {app }}$ and the capacity factor $\eta R$, which are in general both unknown. Besides, also the initial concentration, which is known but prone to measurement errors, is fitted and this is described as the 3-parameter fit. Diffusion coefficients for HTO, reported in this paper have been obtained with this 3-parameter fit. An alternative fit strategy is also possible: assuming $R=1$, only $D_{\text {app }}$ is fitted and $\eta R$ is a constant equal to $\eta_{\text {tot }}$ (measured on either a sample or an average value from literature). In some gas throughdiffusion experiments, the (quasi)stationary state is reached very fast, leading to a nearly total correlation between the capacity factor, the apparent diffusion coefficient, and the initial concentration. In this case, the one parameter fit is the only option and only the effective diffusion coefficient can be determined. Therefore, all diffusion coefficients for dissolved gases are obtained from a one-parameter fit. The one- and three-parameter fits can lead to small differences in the optimal values [23].

The water content of a core was measured at the end of the diffusion experiments, and if this information was not available, a reference value obtained from literature was used (see also Table 3).

As discussed above, confining filters are used in the diffusion experiments. As discussed by Glaus et al. [56], Birgersson and Karnland [57], and Aertsens et al. [48] the filters might have an influence on the results as they contribute to the diffusive resistance of the experiment. Therefore, two fitting strategies are possible: one assuming the same transport parameter values for clay core and filter (case "Filter = Clay" - "F = C") and one with fixed (=the measured but not very accurate values) filter parameter values (case "Fixed Filter," "FF"). However, the only element for which the values of the transport parameters in the filters are measured is HTO [48]. For Boom Clay oriented perpendicular to the bedding plane, the values of the transport parameters are roughly similar to those of the filter so it can be a good approximation to assume the same transport parameters for the filter as for the clay core (case $\mathrm{F}=\mathrm{C})$. However, also Boom Clay cores oriented parallel to the bedding plane and other types of cores are investigated and, in these cases, the diffusion coefficient of the filter differs considerably from the HTO diffusion coefficient in the samples. Therefore, the most correct approach is to use in the model the known HTO filter diffusion coefficient (case fixed filter (FF)). 
TABLE 2: Quantitative mineralogical composition of the different samples (in mass\%) and the specific surface area $\left(\mathrm{m}^{2} / \mathrm{g}\right)$. Minerals which were below the detection limit are indicated with BD.

\begin{tabular}{|c|c|c|c|c|c|c|c|c|c|}
\hline & \multicolumn{3}{|c|}{ Boom Clay } & \multicolumn{3}{|c|}{ Eigenbilzen Sands } & \multirow{2}{*}{ Bentonite } & \multirow{2}{*}{$\mathrm{COX}$} & \multirow{2}{*}{ OPA } \\
\hline & Core $84 \mathrm{~b} \mathrm{~K} 2$ & Core 127b K4 & Core 36a K14 & Core 37b K15 & Core 35b K16 & Core 39b K17 & & & \\
\hline Quartz & 31 & 28 & 59 & 58 & 60 & 54 & 3 & 24 & 28 \\
\hline K-feldspar & 8 & 5 & 8 & 9 & 10 & 8 & $\mathrm{BD}$ & 5 & 3 \\
\hline Plagioclase & 3 & 1 & 6 & 6 & 5 & 5 & 3 & 3 & $\mathrm{BD}$ \\
\hline Calcite & 0.2 & 2 & $\mathrm{BD}$ & $\mathrm{BD}$ & $\mathrm{BD}$ & $\mathrm{BD}$ & $\mathrm{BD}$ & 21 & 8 \\
\hline Ankerite/dolomite & $\mathrm{BD}$ & $\mathrm{BD}$ & $\mathrm{BD}$ & $\mathrm{BD}$ & $\mathrm{BD}$ & $\mathrm{BD}$ & $\mathrm{BD}$ & 4 & $\mathrm{BD}$ \\
\hline Pyrite & 2 & 2 & 0.6 & 0.5 & 1 & 0.5 & $\mathrm{BD}$ & 1 & 0.6 \\
\hline Gypsum* & 0.6 & 0.5 & 1 & 1 & 0 & 0 & $\mathrm{BD}$ & $\mathrm{BD}$ & $\mathrm{BD}$ \\
\hline Anatase & 0.6 & 0.7 & $\mathrm{BD}$ & $\mathrm{BD}$ & $\mathrm{BD}$ & $\mathrm{BD}$ & $\mathrm{BD}$ & $\mathrm{BD}$ & $\mathrm{BD}$ \\
\hline Kaolinite & 8 & 9 & 2 & 4 & 2 & 3 & $\mathrm{BD}$ & 0 & $\mathrm{BD}$ \\
\hline $2: 1$ Al clay & 34 & 41 & 20 & 18 & 21 & 27 & 93 & 39 & $59^{\dagger}$ \\
\hline Muscovite & 9 & 8 & $\mathrm{BD}$ & $\mathrm{BD}$ & $\mathrm{BD}$ & $\mathrm{BD}$ & $\mathrm{BD}$ & $\mathrm{BD}$ & $\mathrm{BD}$ \\
\hline Chlorite & 2 & 2 & 3 & 3.5 & 0 & 2.5 & $\mathrm{BD}$ & 3 & $\mathrm{BD}$ \\
\hline Opal A & 2 & 1 & $\mathrm{BD}$ & $\mathrm{BD}$ & $\mathrm{BD}$ & $\mathrm{BD}$ & $\mathrm{BD}$ & $\mathrm{BD}$ & $\mathrm{BD}$ \\
\hline Specific surface area & 38 & 45 & 14 & 12 & 8 & 20 & + & 28 & 21 \\
\hline
\end{tabular}

${ }^{*}$ Gypsum is a secondary phase; it is an oxidation product of pyrite after exposure of the sample to air; ${ }^{\dagger}$ this value contains all clay minerals (counted together); ${ }^{+}$not measured.

TABLE 3: HTO Diffusion coefficients, fitted capacity factor, and total porosity assuming fixed filter transport parameter values (Fixed Filter, $\mathrm{FF})$.

\begin{tabular}{|c|c|c|c|c|c|c|}
\hline Material & \multicolumn{2}{|c|}{ Core } & $\begin{array}{l}D_{\text {app,FF }} \\
\left(\mathrm{m}^{2} / \mathrm{s}\right)\end{array}$ & $\begin{array}{c}\eta R_{\text {app FF }} \\
(-)\end{array}$ & $\eta_{\text {tot }}$ & $\begin{array}{l}D_{\text {eff,FF }} \\
\left(\mathrm{m}^{2} / \mathrm{s}\right)\end{array}$ \\
\hline Boom Clay & $84 \mathrm{~b}(\mathrm{~K} 2)$ & $\perp$ & $3.4 E-10$ & 0.56 & 0.40 & $1.9 E-10$ \\
\hline Boom Clay & $127 \mathrm{~b}(\mathrm{~K} 4)$ & $/ /$ & $8.7 E-10$ & 0.32 & 0.38 & $2.8 E-10$ \\
\hline Eigenbilzen Sand & 36a (K14) & // & $1.2 E-09$ & 0.27 & 0.39 & $3.2 E-10$ \\
\hline Eigenbilzen Sand & $37 \mathrm{~b}(\mathrm{~K} 15)$ & // & $7.6 E-10$ & 0.58 & 0.40 & $4.4 E-10$ \\
\hline Eigenbilzen Sand & $35 \mathrm{~b}(\mathrm{~K} 16)$ & $\perp$ & $7.6 E-10$ & 0.44 & 0.41 & $3.3 E-10$ \\
\hline Eigenbilzen Sand & 39b (K17) & $\perp$ & $5.5 E-10$ & 0.55 & 0.40 & $3.0 E-10$ \\
\hline Bentonite 1.4 & & & $2.5 E-10$ & 0.62 & $0.47^{*}$ & $1.6 E-10$ \\
\hline Bentonite 1.6 & & & $1.4 E-10$ & 0.58 & $0.4^{*}$ & $8.1 E-11$ \\
\hline COX & & $\perp$ & NM & NM & 0.16 & NM \\
\hline OPA & OPA 1 & $\perp$ & $7.3 E-11$ & 0.17 & 0.096 & $1.2 E-11$ \\
\hline
\end{tabular}

${ }^{*}$ Porosity value from literature [60].

Diffusion coefficients of dissolved gases in the filters are not available and therefore only the value of HTO could be used as an approximation. As this would introduce a large uncertainty into the model and given the large length of the samples $(35 \mathrm{~mm})$ compared to the length of the filters $(2 \times$ $2 \mathrm{~mm}$ ), the effect of the filter on diffusion is not taken into account in the experiments with dissolved gases.

\section{Results}

4.1. Sample Characterization. Both the Boom Clay and the Eigenbilzen Sands are mainly composed of quartz and 2:1 clay minerals. As shown in Table 2, the main differences between the samples of the Boom Clay and the Eigenbilzen Sands are related to the main components quartz and $2: 1$ clay minerals. Given the high quartz content and the lower content of $2: 1$ clay minerals, the samples of the Eigenbilzen
Sands can be considered "sandy" and are categorized as sandy clay.

The composition of the COX sample corresponds well to the reference values presented in [58]. The composition of the Opalinus Clay samples corresponds well to results obtained for samples located nearby our sample [47].

4.2. Hydraulic Conductivity. The hydraulic conductivity $(K)$ values vary over several orders of magnitude (Table 4). The values of the Eigenbilzen Sands (the clayey sand samples ON-Moll core 35b, 36a, 37b, and 39b) display the highest values, which are in line with the reported average value of $3.1 \times 10^{-10} \mathrm{~m} / \mathrm{s}$ for the Eigenbilzen Sands from Aertsens et al. [59], except sample K16 which shows a considerable higher $K$ value and for which we have no clear explanation. The hydraulic conductivity of the "clayey" Boom Clay samples $84 \mathrm{~b}$ and $127 \mathrm{~b}$ (discussed in [23]) is roughly two orders of 


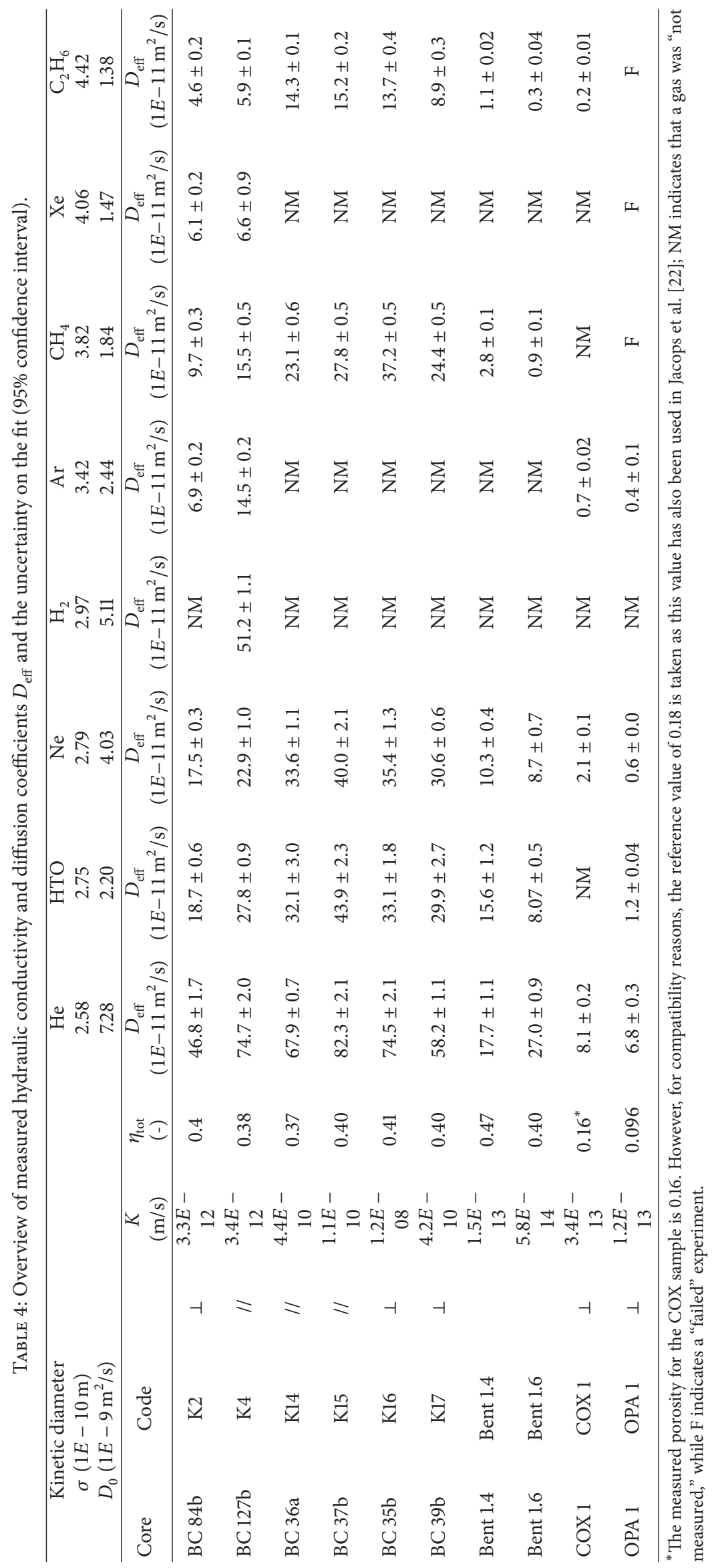


TABLE 5: Geometrical factors obtained from the aqueous and effective diffusion coefficients from Table 4. Note that similar to the previous table, the reference value of 0.18 is used for the COX1 total porosity.

\begin{tabular}{|c|c|c|c|c|c|c|c|c|c|c|c|}
\hline Core & \multicolumn{2}{|c|}{ Code } & $\eta_{\text {tot }}(-)$ & \multicolumn{8}{|c|}{$G(-)$} \\
\hline BC 84b & $\mathrm{K} 2$ & $\perp$ & 0.4 & 6.2 & 4.7 & 9.2 & & 14.1 & 7.6 & 9.6 & 11.9 \\
\hline $\mathrm{BC} 127 \mathrm{~b}$ & K4 & // & 0.38 & 3.7 & 3.0 & 6.7 & 3.8 & 6.4 & 4.5 & 8.4 & 8.9 \\
\hline BC 36a & K14 & // & 0.37 & 4.0 & 2.5 & 4.4 & & & 2.9 & & 3.6 \\
\hline BC 37b & K15 & // & 0.4 & 3.5 & 2.0 & 4.0 & & & 2.6 & & 3.6 \\
\hline BC 35b & K16 & $\perp$ & 0.41 & 4.0 & 2.7 & 4.7 & & & 2.0 & & 4.1 \\
\hline BC 39b & K17 & $\perp$ & 0.4 & 5.0 & 2.9 & 5.3 & & & 3.0 & & 6.2 \\
\hline Bent 1.4 & Bent 1.4 & & 0.47 & 19.3 & 6.6 & 18.4 & & & 30.7 & & 60.3 \\
\hline Bent 1.6 & Bent 1.6 & & 0.4 & 10.8 & 10.9 & 18.5 & & & 79.9 & & 161.7 \\
\hline COX 1 & COX 1 & $\perp$ & 0.18 & 16.1 & & 34.6 & & 60.2 & & & 131.1 \\
\hline OPA 1 & OPA 1 & $\perp$ & 0.096 & 10.2 & 17.5 & 62.1 & & 54.0 & & & \\
\hline
\end{tabular}

magnitude lower. Still an order of magnitude lower is the hydraulic conductivity of the COX and OPA samples [22] and both bentonite samples. Evidently, the 1.6 density bentonite has a lower hydraulic conductivity than the 1.4 bentonite.

Assuming that a soil consists of spherical grains, the pores largely consist of the space between the grains. In a very rough approximation, the pore size is related to the grain size and the sorting of the sedimented particles. Because the grain size of sand is larger than that of clay grains, according to expression (11) the hydraulic conductivity of the Boom Clay samples is expected to be smaller than the hydraulic conductivity of the samples of the Eigenbilzen Sands, which is confirmed by the measurements. Due to the lower porosity of COX and OPA, a lower hydraulic conductivity can be expected than for Boom Clay. Despite their relatively high porosity, the low hydraulic conductivity of the bentonites can be understood by their fine grain size and because of their composition (mainly montmorillonite). The interlayers in montmorillonite, with a thickness of a thin water layer, can be considered as "pores," reducing the typical pore size.

\subsection{Diffusion Experiments}

4.3.1. HTO Diffusion Results. As described above, the HTO experiments are fitted by using fixed filter (FF) values. The results are shown in Table 3. Please note that the value for HTO is now obtained with fixed filter values, while the OPA value in Jacops et al. [22] was obtained considering filter = clay.

For the capacity factors, there is for some samples a considerable difference between the fitted capacity factors and the total porosity $\eta_{\text {tot }}$ (for this parameter, sometimes a reference value is used, and sometimes it is measured by water content), in particular for OPA. However, the error on the fits is small (Table 4); hence the fits are considered to be good.

4.3.2. Diffusion Coefficients and Geometric Factors of Dissolved Gases. All measured effective diffusion coefficients and the corresponding geometrical factors for dissolved gases and HTO are reported in Tables 4 and 5. The COX and OPA (He and Ar) results have already been reported in [22], as well as the Boom Clay samples ON-Moll 84b and 127b in [23]. Please note that the fits for COX were performed with a porosity of $18 \%$, in order to be consistent with Jacops et al. [22].

Opalinus Clay has the lowest porosity of all the samples used in this paper. It is evidently the first candidate showing possible percolation transition problems. These occurred for all gases larger than Argon: $\mathrm{CH}_{4}, \mathrm{Xe}$, and $\mathrm{C}_{2} \mathrm{H}_{6}$ :

(i) For $\mathrm{CH}_{4}$ the measurements were scattered and all below $100 \mathrm{ppm}$. As $100 \mathrm{ppm}$ is the lower limit for reliable $\mathrm{CH}_{4}$ peak detection and measurement, all measurements contain a significant portion of noise and are therefore considered nonsignificant.

(ii) For Xe, no breakthrough was measured which could also be related to the detection limit of $100 \mathrm{ppm}$.

(iii) For $\mathrm{C}_{2} \mathrm{H}_{6}$, where the detection limit is only $5 \mathrm{ppm}$, a clear breakthrough curve was detected, but it could not be fitted by a simple diffusion model (see Figure 1): a quasi-stationary state is reached very soon, but after about 150-200 days, the outlet concentration starts to increase much faster. Because the system is probably very close to the percolation threshold, a possible explanation might be diffusion over another percolating, longer pathway.

When comparing the measured diffusion coefficients in the Boom Clay samples and the samples from the Eigenbilzen Sands, one can observe that despite a comparable porosity, the diffusion coefficients in the Eigenbilzen Sands are slightly higher than in Boom Clay. This agrees with previous results from pulse injection experiments [59], showing on average higher HTO dispersion coefficients in the Eigenbilzen Sands than in Boom Clay. Evidently, the present results confirm that diffusion coefficients are anisotropic and higher for cores parallel to the bedding compared to cores perpendicular to the bedding. Despite its higher porosity compared to the Boom Clay and the Eigenbilzen Sands, the diffusion coefficients in bentonite 1.4 are smaller (as was also the case for the hydraulic conductivity). For helium in bentonite, we observed that diffusion coefficient in bentonite 1.4 is 


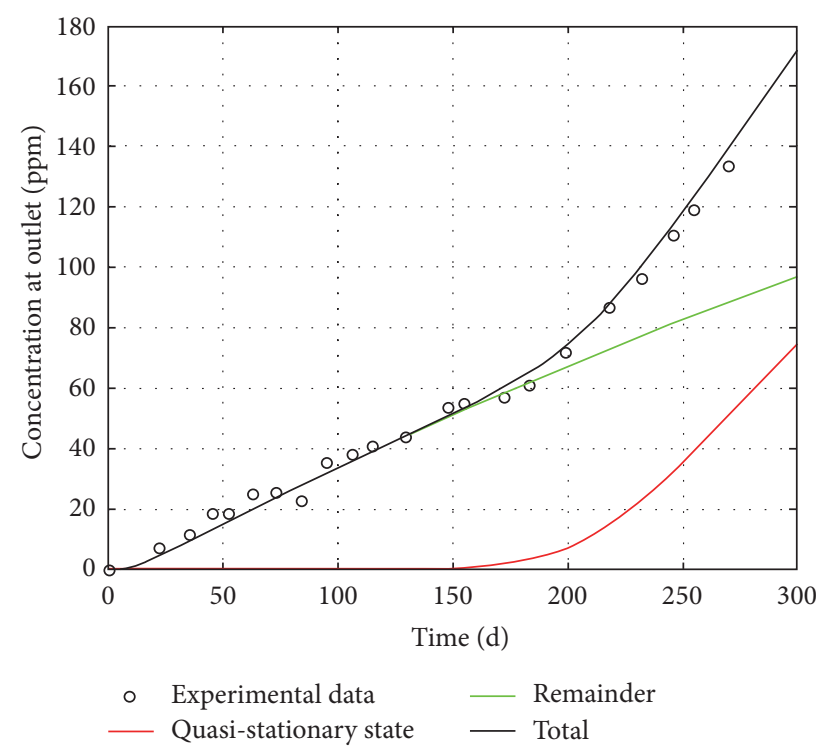

FIGURE 1: Evolution of the outlet concentration versus time in the $\mathrm{C}_{2} \mathrm{H}_{6}$ diffusion experiment in Opalinus Clay. A clear breakthrough after a couple of days, leading to a quasi-stationary state is followed by an sudden unexplained increase after more than 150 days.

considerably lower than for bentonite 1.6. In fact, one would expect the opposite and we cannot explain this observation. The other three gases show the expected behaviour: lower diffusion coefficients in bentonite 1.6 compared to bentonite 1.4. The lowest diffusion coefficients were observed for the clays with the lowest porosity: COX and OPA.

Also, note that, for the samples from the Eigenbilzen Sands and for the Boom Clay samples, the diffusion coefficients for HTO and $\mathrm{Ne}$ (two molecules with a nearly equal kinetic diameter) are about the same. Due the very different values for the HTO and $\mathrm{Ne}$ aqueous diffusion coefficients $\left(D_{0}\right)$, the corresponding geometric factors differ considerably.

\subsubsection{The Effective Diffusion Coefficients and the Geometric} Factor as a Function of the Size of the Diffusing Molecule. Table 6 shows the fitted values according to expression (14) from the measured effective gas diffusion coefficients and the corresponding graphs are shown in Figure 2. Although HTO is included in Table 4, it is not included in the fits (shown in Table 6) as we only describe the data for dissolved gases.

Most of the fits of Table 6 are fair but show a relatively large error. The OPA fit is not reliable: for both fit parameters, the error is larger than $100 \%$.

For all Boom Clay and Eigenbilzen Sands samples, the exponential factor $n_{\exp }$ is on average $(7.9 \pm 2) \times 10^{-10}$ which is similar to the exponential factor $n_{0, \exp }$ of the fit of $D_{0}((8.8 \pm$ $\left.1.2) \times 10^{-9}\right)$. For the other clayey samples, the factor $n_{\exp }$ is always substantially larger than $n_{0 \text {,exp }}$.

As discussed earlier, for gases, the geometric factor $G$ can be calculated from diffusion experiments. Similar to the evolution of $D_{\text {eff }}$ with size; also the evolution of $G$ with size can be described with an exponential or a power law function and this is shown in Figure 3.
From Figure 3 and Table 5, one can observe that for the Boom Clay sample 127b (K4) the geometric factor tends to increase with the kinetic diameter, but the difference in $G$ between the smallest $(\mathrm{He})$ and largest $\left(\mathrm{C}_{2} \mathrm{H}_{6}\right)$ molecule is smaller than a factor 3 .

For the Eigenbilzen Sands samples, the geometric factor is rather a constant value. This can also be deduced from the exponential factors of the fit of $D_{\text {eff }}$ (Table 6): if $n_{0, \exp }$ and $n_{\exp }$ are similar $\left(n_{\exp }-n_{0 \text {,exp }} \approx 0\right)$, according to expression (16), the variation of $G$ with molecular size is small, in agreement with the experimental results (see Table 5).

For the other clayey samples, the geometric factor clearly increases quite spectacularly with the kinetic diameter: the $G$ ratio between smallest and largest molecule ranges from a factor 3 (bentonite 1.4) up to a factor 16 (Bentonite 1.6). This is also reflected in the exponential factors $n_{\exp }$ which differ much more from the $n_{0 \text {,exp }}$ factor compared to the Boom Clay and Eigenbilzen Sands samples (see Table 6).

From the fits in Table 6, the tortuosity $\tau$ (expression (17)) and $R_{\text {pore }}$ (expression (18)) can be calculated. The calculated tortuosity factors $\tau$ are, apart from the unreliable OPA value and the small Bent 1.6 value, quite similar. But the calculated $R_{\text {pore }}$ values are sometimes negative which is physically impossible (Boom Clay sample K2 and the four samples of the Eigenbilzen Sands). For these samples, the values of $n_{0 \text {,exp }}$ and $n_{\text {exp }}$ are within each other's error interval which means that in some cases $n_{0, \exp }>n_{\text {exp }}$, which leads according to expression (18) to negative $R_{\text {pore }}$ values. For these samples, the difference in $D_{\text {eff }}$ between the largest and smallest molecule is about one order of magnitude. So a slight change in one of the $D_{\text {eff }}$ values can strongly influence $n_{\exp }$. This observation points to a limitation of this approach: it can only be used when $n_{\text {exp }}$ differs significantly from $n_{0 \text {,exp }}$. From the measured $K$ values, $R_{\text {pore }, K}$ can be calculated according to expression (11) and these results are also shown in Table 6. When comparing both calculated $R_{\text {pore }}$ values, it is clear that when a reliable exponential fit is obtained, and when $n_{\exp }$ differs significantly from $n_{0 \text {,exp }}$ (so no negative $R_{\text {pore }}$ values) both calculated $R_{\text {pore }}$ values are relatively similar.

According to expression (6) which relates the geometric factor to the size of the diffusing molecule and the pore size, the geometrical factor always increases as a function of the size of the diffusing molecule. For a sufficiently small molecular size $\sigma$ (with respect to the pore size $R_{\text {pore }}$ ) the exponential factor $\exp \left(\sigma / R_{\text {pore }}\right)$ can be approximated by one, so that the geometrical factor is approximately constant. This means that, according to expression (6), the geometric factor for a very small diffusing molecule (kinetic diameter $\sigma \rightarrow 0$ ) is roughly similar in all these clays and the pore size $R_{\text {pore }}$ is not relevant. This applies most to the smallest molecule, helium, for which indeed the variability of $G$ over the different samples is small. From expression (6), one can also conclude that if, for the same sample, all diffusing molecules are sufficiently small compared to the pore size, the geometric factor is also approximately constant. This is the case for the samples of the Eigenbilzen Sands: as $R_{\text {pore } K}$ (calculated from expression (11)) is around $2 \times 10^{-8} \mathrm{~m}$, the pores are much larger than the diffusing molecules. 


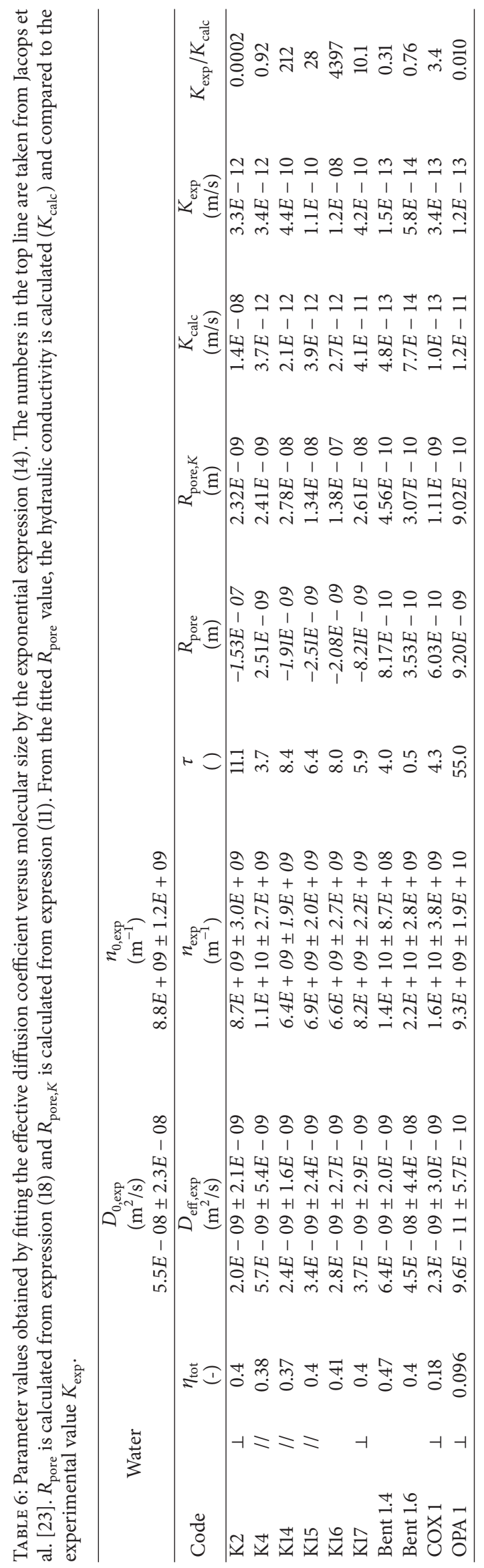




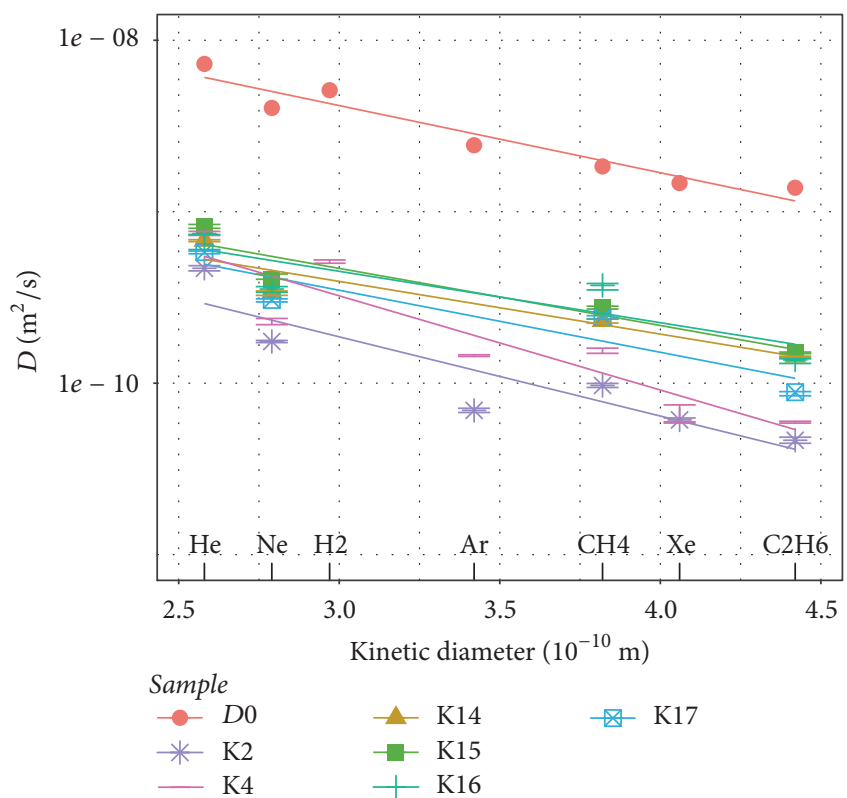

(a)

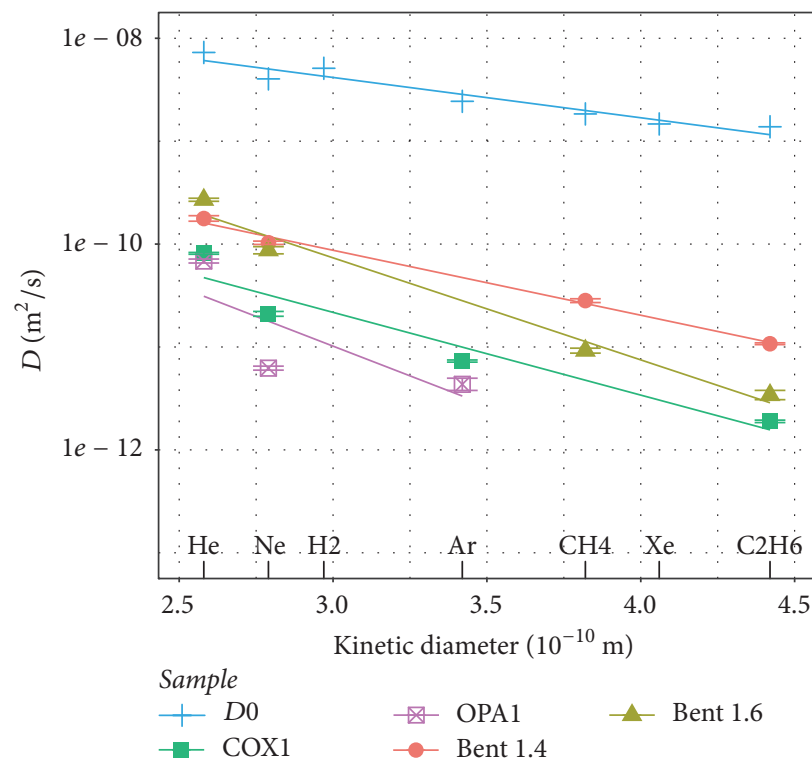

(b)

FIGURE 2: Effective diffusion coefficients for dissolved gases in Boom Clay (a) and other clayey materials (b), fitted with expression (14). The diffusion coefficient $D$ is either the diffusion coefficient $D_{0}$ in pure water or the effective diffusion coefficient $D_{\text {eff }}$ in a porous medium.

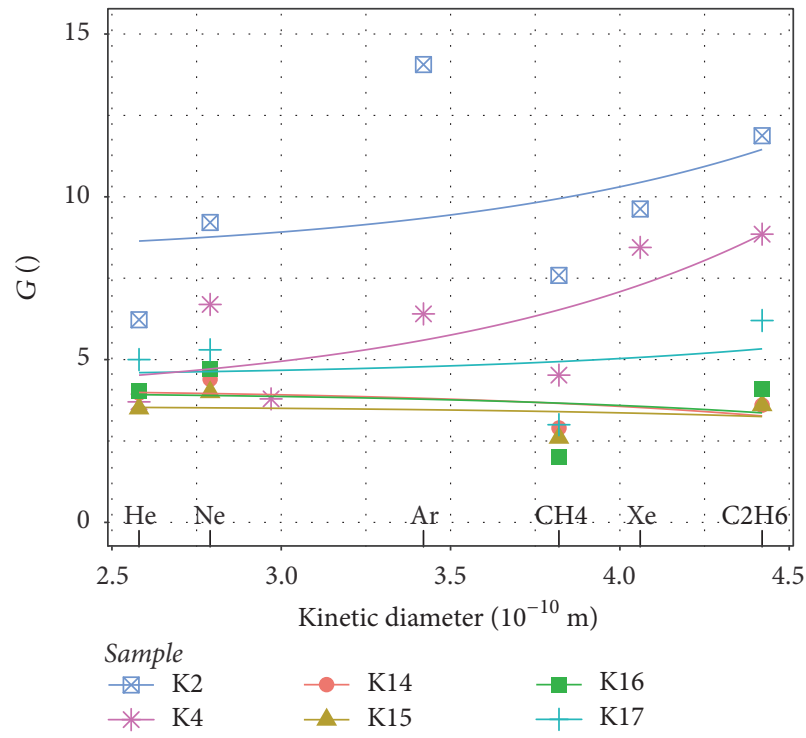

(a)

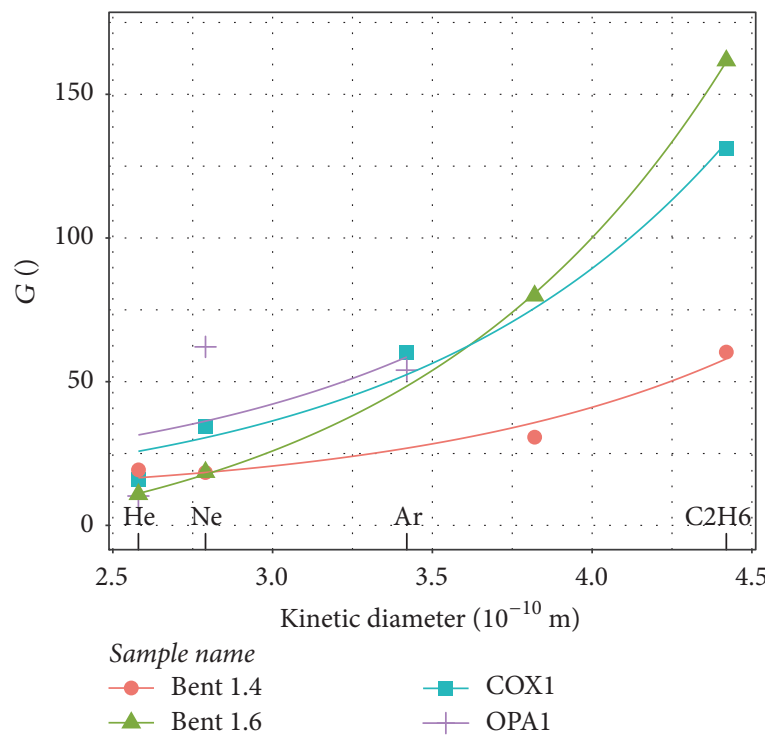

(b)

FIGURE 3: Geometric factors for dissolved gases in Boom Clay (a) and other clayey materials (b).

When the diffusing molecules are not small compared to the pore size, the pore size becomes more important. When, in this case, the size of the diffusing molecule increases, the geometric factors in the different clays diverge, and the geometric factor for different gases in a single sample is not constant. For both bentonites and COX, both fitted $R_{\text {pore }}$ values are small (see Table 6) (similar to the size of the diffusing molecules) and the geometric factor clearly rises with increasing molecular size (see Figure 3). For Boom Clay, sample $\mathrm{K} 4$ which is expected to have larger pores compared to
COX and the bentonites, the geometric factor also increases with the size of the diffusing molecule, although less steeply.

Despite the enormously simplifying assumption to replace a whole pore distribution by just one pore size in both the hydraulic conductivity model and the effective diffusion coefficient versus diffusing molecule size model, both models lead to similar values for the typical pore size. Using the fitted $R_{\text {pore }}$ values to predict the hydraulic conductivity with expression (11) gives quite a good agreement between the calculated hydraulic conductivity $K_{\text {calc }}$ and the experimental 
TABLE 7: Parameter values obtained by fitting the effective diffusion coefficient vs. size of the diffusing molecule by the power law expression (15). The numbers in the top line are taken from [23]. "Tortuosity” $\tau$ is defined similarly as expression (17).

\begin{tabular}{|c|c|c|c|c|c|c|}
\hline & Water & & $\begin{array}{c}D_{0, \text { pow }} \\
\left(\mathrm{m}^{2} / \mathrm{s}\right) \\
1.1 E-07 \pm 4.6 E-08\end{array}$ & $\begin{array}{c}n_{0, \text { pow }} \\
() \\
3.0 \pm 0.4\end{array}$ & & \\
\hline Code & & $\begin{array}{c}\eta_{\text {tot }} \\
(-)\end{array}$ & $\begin{array}{l}D_{\text {eff,pow }} \\
\left(\mathrm{m}^{2} / \mathrm{s}\right)\end{array}$ & $\begin{array}{c}n_{\text {pow }} \\
\left(\mathrm{m}^{-1}\right)\end{array}$ & $\begin{array}{l}\tau \\
()\end{array}$ & $\begin{array}{c}n_{\text {pow }}-n_{0, \text { pow }} \\
()\end{array}$ \\
\hline K2 & $\perp$ & 0.4 & $5.0 E-09 \pm 5.8 E-09$ & $3.2 \pm 0.9$ & 8.4 & 0.2 \\
\hline K4 & // & 0.38 & $1.3 E-08 \pm 1.4 E-08$ & $3.7 \pm 0.9$ & 3.1 & 0.7 \\
\hline K14 & $/ /$ & 0.37 & $4.0 E-09 \pm 3.1 E-09$ & $2.2 \pm 0.6$ & 10.0 & -0.8 \\
\hline K15 & // & 0.4 & $5.9 E-09 \pm 4.8 E-09$ & $2.4 \pm 0.7$ & 6.6 & -0.6 \\
\hline K16 & $\perp$ & 0.41 & $4.8 E-09 \pm 5.5 E-09$ & $2.3 \pm 0.9$ & 8.3 & -0.7 \\
\hline K17 & $\perp$ & 0.4 & $7.0 E-09 \pm 6.8 E-09$ & $2.9 \pm 0.8$ & 5.5 & -0.2 \\
\hline Bent 1.4 & & 0.47 & $1.8 E-08 \pm 7.2 E-09$ & $5.0 \pm 0.3$ & 2.8 & 1.9 \\
\hline Bent 1.6 & & 0.4 & $2.3 E-07 \pm 1.9 E-07$ & $7.5 \pm 0.7$ & 0.2 & 4.5 \\
\hline COX 1 & $\perp$ & 0.18 & $1.0 E-08 \pm 1.3 E-08$ & $5.8 \pm 1.1$ & 1.9 & 2.8 \\
\hline OPA 1 & $\perp$ & 0.096 & $1.1 E-10 \pm 7.1 E-10$ & $2.7 \pm 5.9$ & 94.2 & -0.4 \\
\hline
\end{tabular}

value $K_{\text {exp }}$ for both bentonites, COX and Boom Clay sample K4 (see Table 6). It is straightforward that, for negative $R_{\text {pore }}$ values (sample K2 and the Eigenbilzen Sands), this prediction cannot be good, and it has already been mentioned that the OPA fits are not reliable.

The effective diffusion coefficients can also be fitted as a function of size by using the power law expression (19), leading to the optimal values summarized in Table 7. Apart from the fact that for the power law no typical pore size like $R_{\text {pore }}$ exists, the conclusions are similar as for the exponential fit: a bad fit for OPA, a steep increase of the geometric factor as a function of molecular size for both bentonites and COX, a slower increase for both Boom Clay samples, and a hardto-explain (apart from measurement errors) decrease $\left(n_{\text {pow }}-\right.$ $n_{0 \text {,pow }}<0$ ) for the Eigenbilzen Sands (indicated in italic).

4.4. How to Estimate Gas Diffusion Coefficients as a Function of the Size of the Diffusing Molecule? Based on the results presented in this work, one can state that the approach of using one geometric factor for estimating $D_{\text {eff }}$ of species with a different molecular size is not always correct and the validity depends on the type of sample and the size of the diffusing molecule. For instance, for the Eigenbilzen Sand samples, the geometric factor from HTO could be used to calculate $D_{\text {eff }}$ for, for example, $\mathrm{C}_{2} \mathrm{H}_{6}$. On the contrary, for COX or bentonite, using the geometric factor of HTO to calculate $D_{\text {eff }}$ for $\mathrm{C}_{2} \mathrm{H}_{6}$ would lead to a serious overestimation. In order to illustrate this, we use for COX a geometric factor of 17 for HTO, as suggested by Jacops et al. [22]. If this value would be used to predict $D_{\text {eff }}$ for $\mathrm{C}_{2} \mathrm{H}_{6}$, a value of $1.5 \times 10^{-11} \mathrm{~m}^{2} / \mathrm{s}$ would be obtained while the measured value was $0.2 \times 10^{-11} \mathrm{~m}^{2} / \mathrm{s}$ so this leads to an overestimation of factor 7.

A more correct way to estimate diffusion coefficients would be by using the exponential or power law relation between $D_{\text {eff }}$ and the molecular size (expressions (14) and (15)). Each expression has two parameters, meaning that for two gases the effective diffusion coefficient needs to be determined experimentally. Evidently, it is best to do this for a large molecule (e.g., $\mathrm{C}_{2} \mathrm{H}_{6}$ ) and a small one. He is the smallest of all molecules considered here, but its diffusion coefficients are always higher than expected (located above the fitted curve in Figure 2). This leads to the observation that the measured $D_{\text {eff }}$ is on average 1.7 times larger than the calculated $D_{\text {eff }}$ (see Table 8). For the second smallest molecule (neon), the calculated average $D_{\text {eff }}$ is similar to the measured $D_{\text {eff }}$; hence $\mathrm{Ne}$ is recommended for being used in the fits. An example of such a prediction with the exponential expression (14) is shown in Table 9. Evidently, because $\mathrm{Ne}$ and $\mathrm{C}_{2} \mathrm{H}_{6}$ are used to determine the fit parameters, for both of these gases, the predicted value corresponds exactly to the experimental value. For the other gases, the prediction can be improved by multiplying the predicted diffusion coefficient with the averages of the ratio of the experimental to fitted value for all measured clays (see Table 8). This manipulation allows correcting for the specific bias of this ratio, which is different for each gas. After this correction, for sample K4 (one of the experiments for which most measurements were carried out), apart from $\mathrm{He}$, the predicted and measured effective diffusion coefficients differ up to less than $30 \%$ (see Table 9).

By using this approach, the diffusion coefficient of, for instance, $\mathrm{H}_{2}$ (which is difficult to measure due to microbial activity [24]), can be estimated based on its molecular size. But note that the diffusion coefficient for $\mathrm{H}_{2}$ was (due to experimental difficulties) measured for only one sample; hence the correction factor might be only an estimate.

\section{Conclusion}

Summarizing, for unreactive gases in clayey materials, the effective diffusion coefficient varies with the size of the diffusing molecule and this variation can be described by an exponential or a power law function. Besides, the geometric factor can be described by a decreasing exponential function of the ratio between the size of the diffusing molecule and a characteristic pore size $R_{\text {pore }}$. This means that, in case of a large characteristic pore size (what corresponds 
TABLE 8: Ratios between the experimentally determined $D_{\text {eff }}$ (values see Table 4 ) and the fitted $D_{\text {eff }}$ (using the fits given in Table 6), as well as the averages for each element. Due to the deviating value of He for sample OPA1, the corresponding $D_{\text {eff }}$ is not included in the average.

\begin{tabular}{|c|c|c|c|c|c|c|c|c|}
\hline Core & Code & \multicolumn{7}{|c|}{ Ratio Exp/Fit (-) } \\
\hline BC 84b & K2 & 2.3 & 1.0 & & 0.7 & 1.4 & 1.1 & 1.1 \\
\hline BC $127 b$ & $\mathrm{~K} 4$ & 2.0 & 0.8 & 2.1 & 1.0 & 1.6 & 0.9 & 1.1 \\
\hline BC 36a & K14 & 1.4 & 0.8 & & & 1.1 & & 1.0 \\
\hline BC 37b & K15 & 1.4 & 0.8 & & & 1.2 & & 1.0 \\
\hline BC 35b & K16 & 1.4 & 0.8 & & & 1.6 & & 0.9 \\
\hline BC 39b & K17 & 1.3 & 0.8 & & & 1.5 & & 0.9 \\
\hline Bent 1.4 & Bent 1.4 & 1.1 & 0.9 & & & 1.1 & & 1.0 \\
\hline Bent 1.6 & Bent 1.6 & 1.7 & 0.8 & & & 0.8 & & 1.2 \\
\hline $\operatorname{COX} 1$ & COX 1 & 2.4 & 0.9 & & 0.9 & & & 1.2 \\
\hline OPA 1 & OPA 1 & 7.8 & 0.9 & & 1.1 & & & \\
\hline \multicolumn{2}{|l|}{ Average } & 1.7 & 0.8 & 2.1 & 0.9 & 1.3 & 1.0 & 1.0 \\
\hline \multicolumn{2}{|c|}{ Standard deviation } & 0.4 & 0.1 & & 0.2 & 0.3 & 0.2 & 0.1 \\
\hline
\end{tabular}

${ }^{*}$ For $\mathrm{He}$, OPA1 not included.

TABle 9: Predicting the gas effective diffusion coefficients of sample $\mathrm{K} 4$ after measuring the $\mathrm{Ne}$ and $\mathrm{C}_{2} \mathrm{H}_{6}$ (both in italic) effective diffusion coefficients. In a first phase, the prediction is based only on expression (14). Subsequently, this prediction is improved by multiplication with a "correction factor" (see Table 8), which takes into account the gas specific deviation between the experimental and the predicted value.

\begin{tabular}{|c|c|c|c|c|c|c|c|c|}
\hline & & $\mathrm{He}$ & $\mathrm{Ne}$ & $\mathrm{H}_{2}$ & $\mathrm{Ar}$ & $\mathrm{CH}_{4}$ & $\mathrm{Xe}$ & $\mathrm{C}_{2} \mathrm{H}_{6}$ \\
\hline Kinetic diameter $\sigma$ & $(1 E-10 \mathrm{~m})$ & 2.58 & 2.79 & 2.97 & 3.42 & 3.82 & 4.06 & 4.42 \\
\hline$D_{\text {eff }}$ (experiment) & $\left(1 E-11 \mathrm{~m}^{2} / \mathrm{s}\right)$ & 74.7 & 22.9 & 51.2 & 14.5 & 15.5 & 6.6 & 5.9 \\
\hline$D_{\text {eff }}$ (prediction) & $\left(1 E-11 \mathrm{~m}^{2} / \mathrm{s}\right)$ & 27.2 & 22.9 & 19.7 & 13.6 & 9.7 & 8.0 & 5.9 \\
\hline Ratio $D_{\text {eff }}(\exp ) / D_{\text {eff }}$ (pred) & ( ) & 2.7 & 1.0 & 2.6 & 1.1 & 1.6 & 0.8 & 1.0 \\
\hline Correction factor & ( ) & 1.7 & 0.8 & 2.1 & 0.9 & 1.3 & 1.0 & 1.0 \\
\hline$D_{\text {eff }}($ pred $) *$ Corr factor & $\left(1 E-11 \mathrm{~m}^{2} / \mathrm{s}\right)$ & 45.8 & & 41.2 & 12.2 & 12.4 & 7.7 & \\
\hline Ratio $D_{\text {eff }}(\exp ) /\left(D_{\text {eff }}\right.$ (pred $) *$ Corr factor $)$ & ( ) & 1.6 & & 1.2 & 1.2 & 1.2 & 0.9 & \\
\hline
\end{tabular}

to a higher hydraulic conductivity) and a small diffusing molecule, the geometric factor (being the ratio of the aqueous diffusion coefficient and the apparent diffusion coefficient) is approximately constant or slowly increasing as a function of the size of the diffusing molecule. For an increasing size of the diffusing molecule, the increase of the geometric factor is expected to become more steep, proportional to the increase of the path length caused by the nonavailability of pore sizes smaller than the molecular size. Such a steep increase is observed for small diffusing molecules in clays with a small characteristic pore size (corresponding to a low hydraulic conductivity). If the size of the diffusing molecule still increases, there is no longer a path of sufficiently large pores connecting both sides of the clay, and the diffusion coefficient becomes zero. Experimental problems due to such a percolation threshold were observed in Opalinus Clay for gas molecules larger than argon. For samples of the Eigenbilzen Sands, we observed that an increase in sand content results in an increased hydraulic conductivity, an increase in diffusivity, and less variability of $G$ with the size of the diffusing molecule.

By measuring experimentally the effective (or apparent) diffusion coefficient of two unreactive gases in clay, the remaining diffusion coefficients can be estimated by an exponential (or alternatively a power law) relationship.

\section{Conflicts of Interest}

The authors declare that they have no conflicts of interest.

\section{Acknowledgments}

This work is partly performed in close cooperation with and with the financial support of ONDRAF/NIRAS, the Belgian Agency for Radioactive Waste and Fissile Materials, as part of the programme on geological disposal that is carried out by ONDRAF/NIRAS. This work has been performed with the support of Tom Maes, Marc Van Gompel, Dorien Verhaegen, Serge Labat, Joan Govaerts, Lander Frederickx, Mieke de Craen, Rieko Adriaens, and Nancy Weyns.

\section{References}

[1] L. Johnson, Project Opalinus Clay: safety report: demonstration of disposal feasibility for spent fuel, vitrified high-level waste and long-lived intermediate-level waste (Entsorgungsnachweis), NAGRA, 2002.

[2] ONDRAF/NIRAS, SAFIR 2: Belgian RD Programme on the Deep Disposal of High-level and Long-lived Radioactive Waste, Brussels, Belgium, 2001. 
[3] "Argile: architecture and management of a geological repository," ANDRA Dossier 2005 In: ANDRA, Châtenay-Malabry, France.

[4] O. Karnland, U. Nilsson, H. Weber, and P. Wersin, "Sealing ability of wyoming bentonite pellets foreseen as buffer materialLaboratory results," Physics and Chemistry of the Earth, vol. 33, no. 1, pp. S472-S475, 2008.

[5] C. A. Davy, F. Skoczylas, P. Lebon, and T. Dubois, "Gas migration properties through a bentonite/argillite interface," Applied Clay Science, vol. 42, no. 3-4, pp. 639-648, 2009.

[6] P. Wikberg, "The outcome of scientific research and its implementation in the Swedish nuclear waste disposal programme," ATW-Internationale Zeitschrift fur Kernenergie, vol. 57, no. 2, pp. 102-105, 2012.

[7] N. Maes, L. Wang, G. Delécault et al., "Galson D (2004) Migration Case Study : Transport of radionuclides in a Reducing Clay Sediment (TRANCOM 2) Contract No FIKW-CT-200000008," EUR-21022, 2004.

[8] N. Maes, S. Salah, D. Jacques et al., "Retention of Cs in Boom Clay: comparison of data from batch sorption tests and diffusion experiments on intact clay cores," Physics and Chemistry of the Earth, vol. 33, no. 1, pp. S149-S155, 2008.

[9] S. Altmann, C. Tournassat, F. Goutelard, J.-C. Parneix, T. Gimmi, and N. Maes, "Diffusion-driven transport in clayrock formations," Applied Geochemistry, vol. 27, no. 2, pp. 463-478, 2012.

[10] C. P. Enssle, M. Cruchaudet, J. Croisé, and J. Brommundt, "Determination of the permeability of the Callovo-Oxfordian clay at the metre to decametre scale," Physics and Chemistry of the Earth, vol. 36, no. 17-18, pp. 1669-1678, 2011.

[11] L. Yu, B. Rogiers, M. Gedeon, J. Marivoet, M. de Craen, and D. Mallants, "A critical review of laboratory and in-situ hydraulic conductivity measurements for the Boom Clay in Belgium," Applied Clay Science, vol. 75-76, pp. 1-12, 2013.

[12] M. Van Geet, W. Bastiaens, and L. Ortiz, "Self-sealing capacity of argillaceous rocks: review of laboratory results obtained from the SELFRAC project," Physics and Chemistry of the Earth, vol. 33, no. 1, pp. S396-S406, 2008.

[13] C.-L. Zhang, "Sealing of fractures in claystone," Journal of Rock Mechanics and Geotechnical Engineering, vol. 5, no. 3, pp. 214220, 2013.

[14] T. Labalette, P. Landais, S. Farin, and G. Ouzounian, "Site selection for a geological repository in France," in Proceedings of the WM2010 Conference, France, 2010.

[15] H. Hökmark, A. Ledesma, T. Lassabatere et al., "Modelling heat and moisture transport in the ANDRA/SKB temperature buffer test," Physics and Chemistry of the Earth, vol. 32, no. 8-14, pp. 753-766, 2007.

[16] P. Sellin and O. X. Leupin, "The use of clay as an engineered barrier in radioactive-waste management-A review," Clays and Clay Minerals, vol. 61, no. 6, pp. 477-498, 2013.

[17] J. Salas, C. Sena, and D. Arcos, "Hydrogeochemical evolution of the bentonite buffer in a KBS-3 repository for radioactive waste. Reactive transport modelling of the LOT A2 experiment," Applied Clay Science, vol. 101, pp. 521-532, 2014.

[18] A. Battani, T. Smith, J. C. Robinet, J. Brulhet, B. Lavielle, and D. Coelho, "Contribution of logging tools to understanding helium porewater data across the Mesozoic sequence of the East of the Paris Basin," Geochimica et Cosmochimica Acta, vol. 75, no. 23, pp. 7566-7584, 2011.
[19] M. Mazurek, P. Alt-Epping, A. Bath et al., "Natural tracer profiles across argillaceous formations," Applied Geochemistry, vol. 26, no. 7, pp. 1035-1064, 2011.

[20] R. Rebeix, C. Le Gal La Salle, P. Jean-Baptiste et al., "Chlorine transport processes through a $2000 \mathrm{~m}$ aquifer/aquitard system," Marine and Petroleum Geology, vol. 53, pp. 102-116, 2014.

[21] E. Jacops, G. Volckaert, N. Maes, E. Weetjens, and J. Govaerts, "Determination of gas diffusion coefficients in saturated porous media: He and CH4 diffusion in Boom Clay," Applied Clay Science, vol. 83-84, pp. 217-223, 2013.

[22] E. Jacops, N. Maes, C. Bruggeman, and A. Grade, "Measuring diffusion coefficients of dissolved $\mathrm{He}$ and $\mathrm{Ar}$ in three potential clay host formations: Boom Clay, Callovo-Oxfordian Clay and Opalinus Clay," Geological Society, vol. 443, 2016, Special Publications.

[23] E. Jacops, M. Aertsens, N. Maes et al., "Interplay of molecular size and pore network geometry on the diffusion of dissolved gases and HTO in Boom Clay," Applied Geochemistry, vol. 76, pp. 182-195, 2017.

[24] E. Jacops, K. Wouters, G. Volckaert et al., "Measuring the effective diffusion coefficient of dissolved hydrogen in saturated Boom Clay," Applied Geochemistry, vol. 61, pp. 175-184, 2015.

[25] A. Vinsot, C. A. J. Appelo, M. Lundy et al., "In situ diffusion test of hydrogen gas in the Opalinus Clay," Geological Society, London, Special Publications, vol. 400, no. 1, pp. 563-578, 2014.

[26] OECD NEA, Natural Tracer Profiles Across Argillaceous Formations, OECD Publishing, 2008.

[27] E. Fourré, P. Jean-Baptiste, A. Dapoigny et al., "Dissolved helium distribution in the Oxfordian and Dogger deep aquifers of the Meuse/Haute-Marne area," Physics and Chemistry of the Earth, vol. 36, no. 17-18, pp. 1511-1520, 2011.

[28] G. Archie, "The electrical resistivity log as an aid in determining some reservoir characteristics," Transactions of the AIME, vol. 146, no. 01, pp. 54-62, 1942.

[29] B. P. Boudreau, "The diffusive tortuosity of fine-grained unlithified sediments," Geochimica et Cosmochimica Acta, vol. 60, no. 16, pp. 3139-3142, 1996.

[30] K. P. Saripalli, R. J. Serne, P. D. Meyer, and B. P. McGrail, "Prediction of diffusion coefficients in porous media using tortuosity factors based on interfacial areas," Groundwater, vol. 40, no. 4, pp. 346-352, 2002.

[31] H. Chou, L. Wu, L. Zeng, and A. Chang, "Evaluation of solute diffusion tortuosity factor models for variously saturated soils," Water Resources Research, vol. 48, p. W10539, 2012.

[32] J.-C. Robinet, P. Sardini, D. Coelho et al., "Effects of mineral distribution at mesoscopic scale on solute diffusion in a clayrich rock: example of the Callovo-Oxfordian mudstone (Bure, France)," Water Resources Research, vol. 48, no. 5, Article ID W05554, 2012.

[33] L. M. Keller, A. Hilger, and I. Manke, "Impact of sand content on solute diffusion in Opalinus Clay," Applied Clay Science, vol. 112-113, pp. 134-142, 2015.

[34] H. L. Weissberg, "Effective diffusion coefficient in porous media," Journal of Applied Physics, vol. 34, no. 9, pp. 2636-2639, 1963.

[35] R. V. H. Dagnelie, M. Descostes, I. Pointeau et al., "Sorption and diffusion of organic acids through clayrock: comparison with inorganic anions," Journal of Hydrology, vol. 511, pp. 619-627, 2014.

[36] Z. Bajja, W. Dridi, B. Larbi, and P. Le Bescop, "The validity of the formation factor concept from through-out diffusion tests 
on Portland cement mortars," Cement and Concrete Composites, vol. 63, pp. 76-83, 2015.

[37] N. Vandenberghe, M. de Craen, and L. Wouters, The Boom Clay Geology. From sedimentation to present-day occurrence: a review, Belgian Institute of Natural Sciences, Geological Survey of Belgium, Brussels, Belgium, Royal, 2014.

[38] M. Honty and M. de Craen, Boom Clay mineralogy-qualitative and quantitative aspects SCK-CEN ER-194, Mol, Belgium, 2012.

[39] National commission for stratigraphy Belgium, Eigenbilzen formation, 2017.

[40] E. Gaucher, C. Robelin, J. M. Matray et al., "ANDRA underground research laboratory: interpretation of the mineralogical and geochemical data acquired in the Callovian-Oxfordian formation by investigative drilling," Physics and Chemistry of the Earth, vol. 29, no. 1, pp. 55-77, 2004.

[41] M. Mazurek, A. J. Hurford, and W. Leu, "Unravelling the multistage burial history of the Swiss Molasse Basin: integration of apatite fission track, vitrinite reflectance and biomarker isomerisation analysis," Basin Research, vol. 18, no. 1, pp. 27-50, 2006.

[42] S. T. Horseman, J. F. Harrington, and P. Sellin, "Gas migration in clay barriers," Engineering Geology, vol. 54, no. 1-2, pp. 139-149, 1999.

[43] A. Sneyers, Understanding and Physical and Numerical Modelling of the Key Processes in the Near Field and their Coupling for Different Host Rocks and Repository Strategies (NF-PRO) EUR 23730, Luxembourg, 2008.

[44] P. Van Marcke, L. XL, G. J. Chen, J. Verstricht, W. Bastiaens, and X. Sillen, "Installation of the PRACLAY Seal and Heater," in Clays in, Naural and Engineered Barriers for Radioacive Wase Confinemen, Norris S et al., Ed., vol. 400, pp. 107-115, Geological Soc Publishing House, 2014.

[45] R. Adriaens, Neogene and Quaternary clay minerals in the southern North Sea, KU Leuven, Leuven, Belgium, 2015.

[46] E. Zeelmaekers, M. Honty, A. Derkowski et al., "Qualitative and quantitative mineralogical composition of the Rupelian Boom Clay in Belgium," Clay Minerals, vol. 50, no. 2, pp. 249-272, 2015.

[47] P. Wersin, M. Mazurek, H. N. Waber et al., Rock and Porewater Characterisation on Drillcores from the Schlattingen Borehole. Nagra Arbeitsbericht, Wettingen, Switzerland, 2012.

[48] M. Aertsens, J. Govaerts, N. Maes, and L. Van Laer, "Consistency of the strontium transport parameters in Boom Clay obtained from different types of experiments: accounting for the filter plates," in Proceedings of the MRS Symposium Proceedings. Scientific Basis for Nuclear Waste Management XXXV, Buenos Aires, pp. 583-589, Argentina, 2011.

[49] I. Wemaere, J. Marivoet, and S. Labat, "Hydraulic conductivity variability of the Boom Clay in north-east Belgium based on four core drilled boreholes," Physics and Chemistry of the Earth, vol. 33, no. 1, pp. S24-S36, 2008.

[50] C. D. Shackelford, "Laboratory diffusion testing for waste disposal-A review," Journal of Contaminant Hydrology, vol. 7, no. 3, pp. 177-217, 1991.

[51] P. Grathwohl, Diffusion in Natural Porous Media: Contaminant Transport, Sorption/desorption and Dissolution Kinetics, Springer, USA, 1998.

[52] D. Durce, M. Aertsens, C. Bruggeman et al., Water-Soluble Organic Matter in Boom Clay: Status report 2012-2016, SCKCEN, Mol, Belgium, 2017.

[53] D. Stauffer and A. Aharony, Introduction to percolation theory London, Taylor Francis, London, UK, 1992.
[54] S. Matteucci, Y. Yampolskii, B. D. Freeman, and I. Pinnau, "Transport of gases and vapors in glassy and rubbery polymers," in Materials Science of Membranes for Gas and Vapor Separation, pp. 1-47, John Wiley \& Sons, 2006.

[55] J. Hirschfelder, C. Curtiss, and R. Bird, Molecular Theory of Gases and Liquids, Wiley, NY, USA, 1964.

[56] M. A. Glaus, R. Rossé, L. R. van Loon, and A. E. Yaroshchuk, "Tracer diffusion in sintered stainless steel filters: measurement of effective diffusion coefficients and implications for diffusion studies with compacted clays," Clays and Clay Minerals, vol. 56, no. 6, pp. 677-685, 2008.

[57] M. Birgersson and O. Karnland, "Ion equilibrium between montmorillonite interlayer space and an external solutionConsequences for diffusional transport," Geochimica et Cosmochimica Acta, vol. 73, no. 7, pp. 1908-1923, 2009.

[58] "La production et le transfert de gaz dans le stockage et la couche du Callovo-Oxfordien," ANDRA , CNTASCM030042. Chatenay-Malabry, France, 2005.

[59] M. Aertsens, A. Dierckx, M. Put et al., Determination of the hydraulic conductivity, the product $\eta \mathrm{R}$ of the porosity $\eta$ and the retardation factor $\mathrm{R}$, and the apparent diffusion coefficient $\mathrm{Dp}$ on Boom Clay cores from the Mol-1 drilling, SCK CEN-R-3503, Belgium, 2005.

[60] L. R. Van Loon, M. A. Glaus, and W. Müller, "Anion exclusion effects in compacted bentonites: towards a better understanding of anion diffusion," Applied Geochemistry, vol. 22, no. 11, pp. 2536-2552, 2007. 

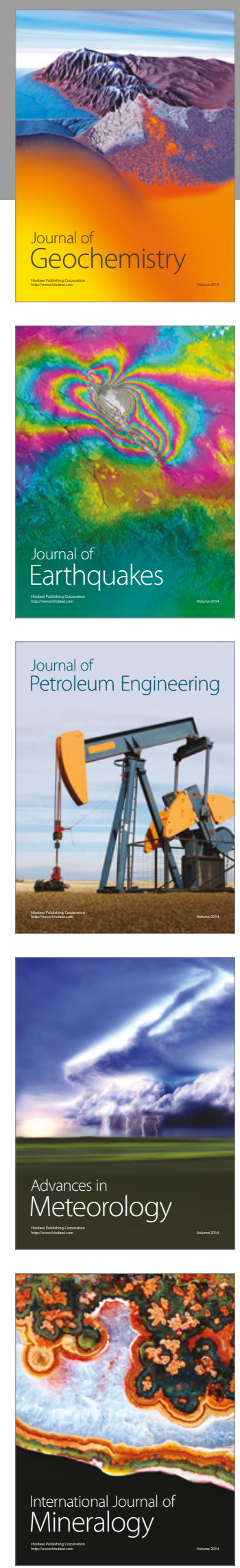
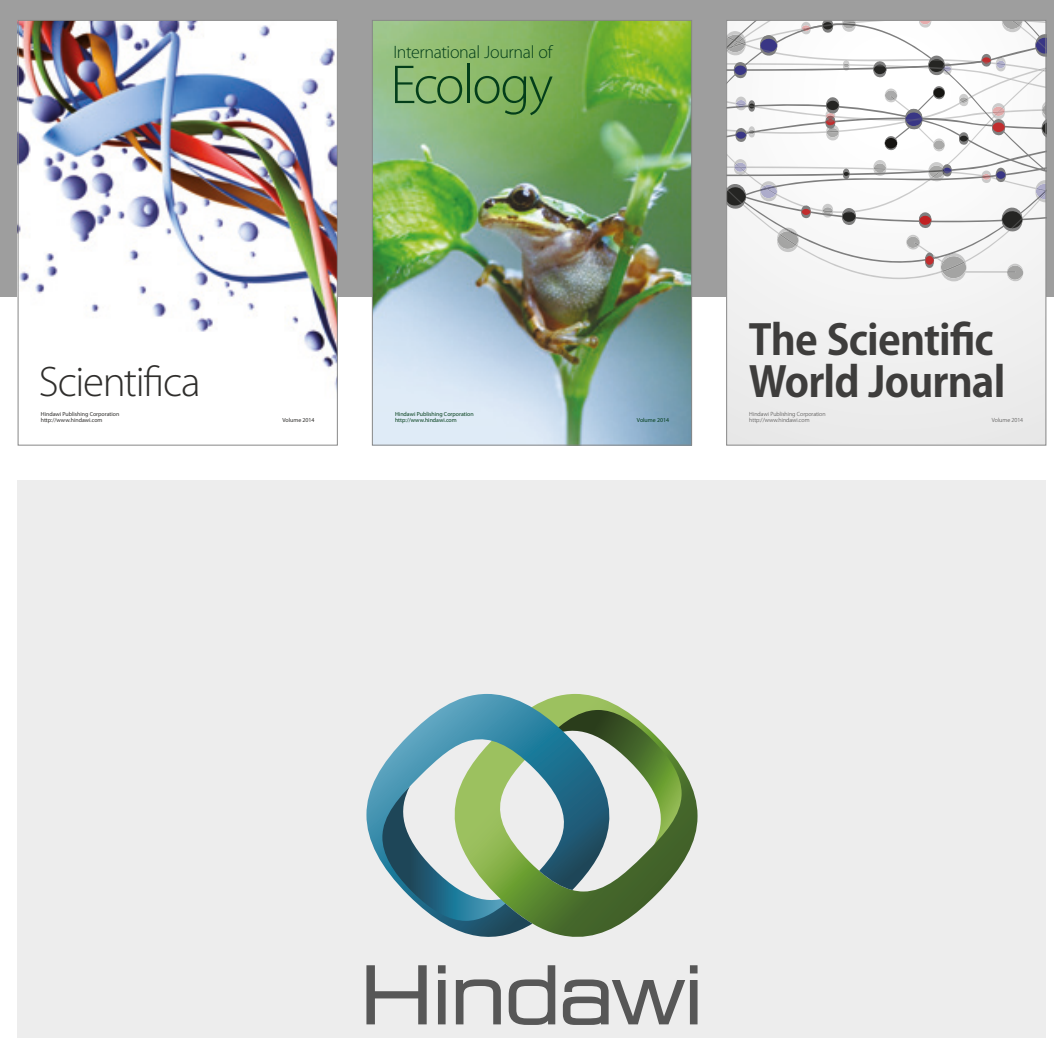

Submit your manuscripts at

https://www.hindawi.com
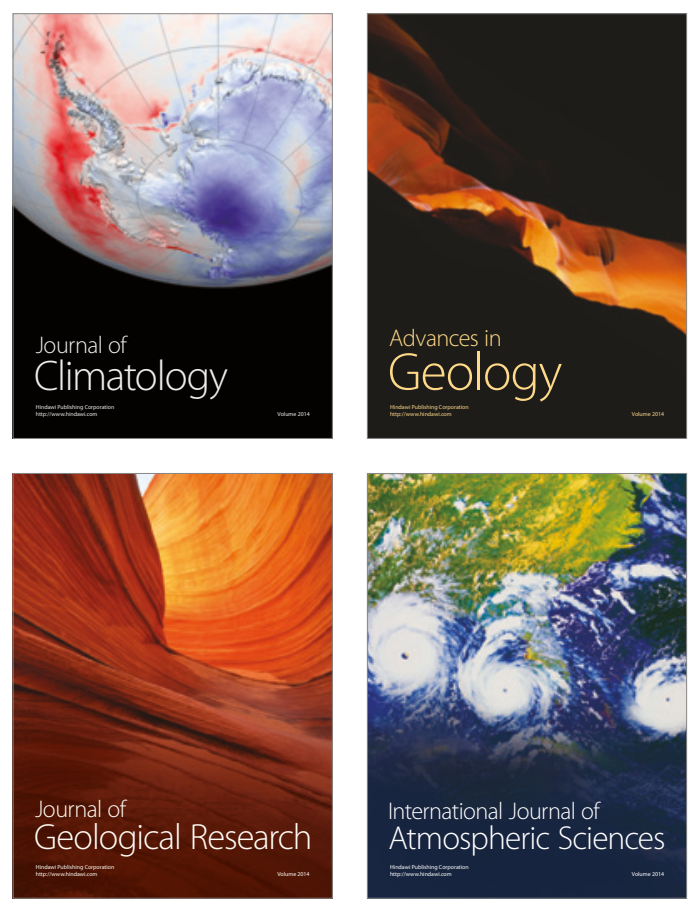

The Scientific

World Journal
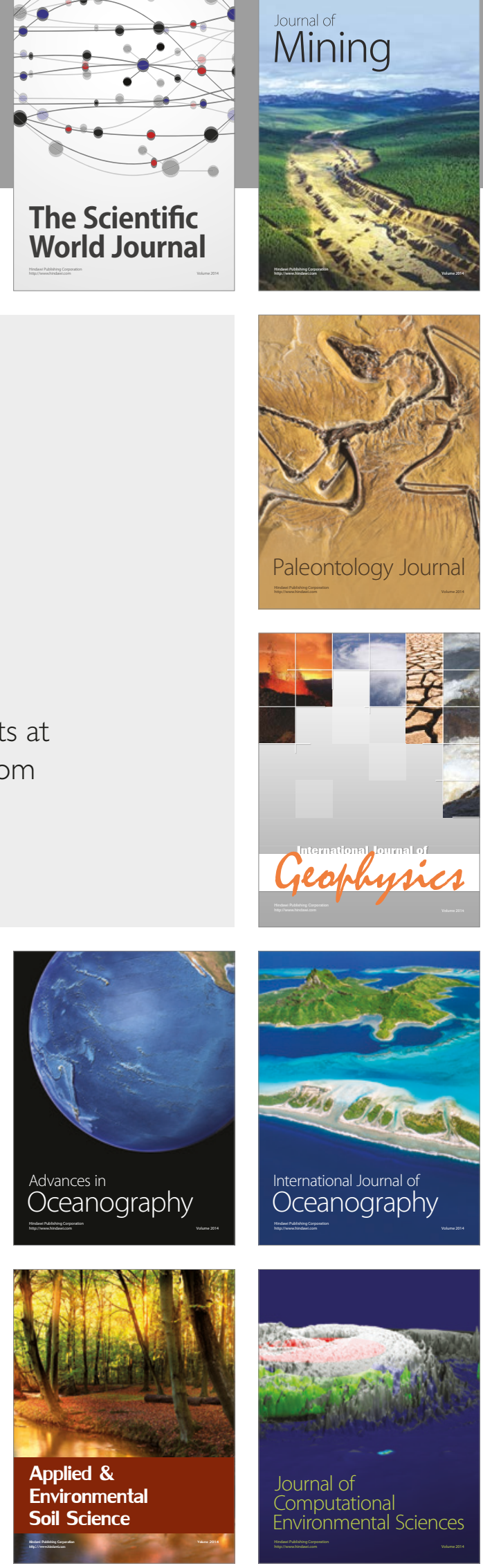